\title{
Deformation Characteristics of the Intermetallic Alloy 60NiTi
}

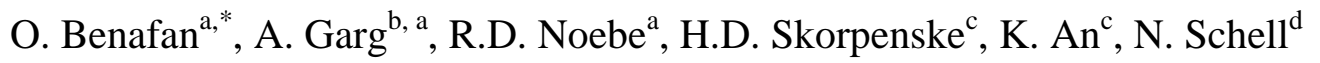

${ }^{a}$ NASA Glenn Research Center, Materials and Structures Division, Cleveland, OH 44135, USA

${ }^{\mathrm{b}}$ University of Toledo, Toledo, OH 43606, USA

${ }^{\mathrm{c}}$ Spallation Neutron Source, Oak Ridge National Laboratory, Oak Ridge, TN 37831, USA

${ }^{\mathrm{d}}$ Institute of Materials Research, Helmholtz-Zentrum Geesthacht, Max-Planck-Str. 1, D-21502

Geesthacht, Germany

*Corresponding author: Tel.: +1 (216) 433 8538; fax: +1 (216) 977-7132.

E-mail address: othmane.benafan@nasa.gov (O. Benafan).

Abstract - The deformation behavior of a Ni-rich $\mathrm{Ni}_{55} \mathrm{Ti}_{45}$ (at.\%) alloy, commonly known as 60NiTi (as designated in wt.\%), was analyzed using neutron and synchrotron x-ray diffraction during in situ isothermal tension and compression loading, and pre and post-test electron microscopy. The alloy is shown to exhibit remarkable strength and high hardness resulting from a high density of fine $\mathrm{Ni}_{4} \mathrm{Ti}_{3}$ precipitates (size $\sim 67 \mathrm{~nm}$ ), which were uniformly dispersed throughout the matrix after a solution treatment and oil quench. The precipitate volume fraction was $55 \pm 3 \%$, determined from both the neutron Rietveld refinement and conventional $x$-ray measurements. Non-linear stress-strain behavior was observed in tension (but not in compression) and was attributed to reversible stress-induced martensite (SIM) that forms to accommodate the stress as revealed by neutron diffraction measurements. The tensile and compressive neutron data also showed peak broadening and residual lattice strains. Transmission and scanning electron microscopy revealed stress-induced coarsening of $\mathrm{Ni}_{4} \mathrm{Ti}_{3}$ precipitates in both tension and compression tested samples, but precipitation and growth of the stable $\mathrm{Ni}_{3} \mathrm{Ti}$ phase was observed only after tensile testing. Finally, the potential ramifications of these microstructural changes are discussed. 
Keywords: 60NiTi; shape memory alloy; stress-induced martensite; strain-induced coarsening; bearing; $\mathrm{Ni}_{4} \mathrm{Ti}_{3}$ precipitates.

\section{Introduction}

NiTi shape memory alloys (SMAs) possess a number of multifunctional properties resulting from a reversible martensitic transformation. NiTi-based SMAs have been shown to exhibit the shape memory effect (thermally-induced transformation) and superelasticity (mechanicallyinduced transformation) depending on composition, processing methods, and other factors. Typically, near-equiatomic and Ti-rich compositions have been exploited for their solid-state actuation potential in automotive [1], aerospace and household appliances [2], amongst others. Slightly Ni-rich compositions of about 50.1 to 52 at.\% Ni have been predominantly used for the

biomedical industry for their distinct body-temperature superelastic phenomenon. Alloys with higher nickel content (e.g., 52 to 57 at.\% Ni), although not commonly used, have an advantageous set of properties for structural applications such as high hardness, corrosion resistance and low density with potential applications in hydrospace, tribology, and toolmanufacturing applications [3].

In the more $\mathrm{Ni}$-rich $\mathrm{NiTi}$ alloys, one widely studied composition is $\mathrm{Ni}_{55} \mathrm{Ti}_{45}$ (at.\%), commonly referred to as 60 -NiTiNOL or $60 \mathrm{NiTi}$ for its composition designated in weight percent. $60 \mathrm{NiTi}$ is an ordered, intermetallic compound consisting of a B2, cubic crystal structure matrix containing one or more secondary phases including the metastable $\mathrm{Ni}_{4} \mathrm{Ti}_{3}$ and $\mathrm{Ni}_{3} \mathrm{Ti}_{2}$ phases, and the equilibrium $\mathrm{Ni}_{3} \mathrm{Ti}$ phase. Dating back to the 1960s, this specific composition has been investigated as a function of heat treatments/ageing [3-6], thermomechanical processing of ingot and powder samples [7, 8], and occasional theoretical studies [9]. Depending on the 
specific processing parameters, this alloy can be tailored for actuation purposes [10-13], tribological applications [14], tools and cutlery [3, 15, 16], and biomedical surfaces [17], while derivative alloys are being explored in attempts to optimize properties for some of these applications [18].

While the shape memory behavior displayed by this alloy is foreseeable, the reason for the high hardness has only recently been explored $[6,18]$, and the fact that these very high strength alloys can also exhibit extended inelastic deformation [19] is still not fully understood. Unlike typical superelastic behavior where a hysteresis-dominant, flag-like response is observed, these alloys under certain conditions exhibit a large, reversible inelastic deformation with nearly no hysteresis and yield stresses in excess of $2.5 \mathrm{GPa}$. Thus, the purpose of this work is to investigate the deformation characteristics of the 60NiTi under heat treatments that result in a very hard material with a very high load carrying capability and large recoverable strains. The current analysis includes in situ neutron and synchrotron diffraction results, and ex situ mechanical deformation in tension and compression and electron microscopy.

\section{Material and procedures}

\subsection{Material}

A binary $\mathrm{Ni}$-rich $\mathrm{Ni}_{55} \mathrm{Ti}_{45}$ (at.\%) alloy was produced by vacuum induction melting of relatively high-purity elemental constituents in a graphite crucible. The resulting ingot (weighting approx. $500 \mathrm{~g}$ ) was vacuum homogenized for 72 hours at $1050{ }^{\circ} \mathrm{C}$ and furnace cooled followed by hot extrusion at $900{ }^{\circ} \mathrm{C}$ through an area reduction ratio of $7: 1$. Test specimens were machined from the extruded rod (Ext. 94) and subjected to a solutionizing treatment of 2.5 hours at $977 \pm 2{ }^{\circ} \mathrm{C}$ followed by oil quenching. This heat treatment was chosen to ensure dissolution of 
the $\mathrm{Ni}_{3} \mathrm{Ti}$ and $\mathrm{Ni}_{3} \mathrm{Ti}_{2}$ phases resulting from the extrusion process while minimizing the potential for grain growth at higher temperatures.

\subsection{Microstructural characterization}

The microstructure of the $\mathrm{Ni}_{55} \mathrm{Ti}_{45}$ alloy was examined at room temperature in the asextruded condition, after the solutionizing treatment $\left(977^{\circ} \mathrm{C} / 2.5 \mathrm{hrs} / \mathrm{OQ}\right)$, and after mechanical testing of the solution-treated material. Samples for optical and scanning electron microscopy (SEM) were mounted, polished, and etched lightly using a solution of $10 \% \mathrm{HF}, 40 \% \mathrm{HNO} 3$ and $50 \% \mathrm{H} 2 \mathrm{O}$ (by volume) to reveal grain size. SEM samples were examined in a Hitachi 4700 microscope equipped with an IXRF energy-dispersive $\mathrm{x}$-ray spectroscopy (EDS) detector for composition analysis. Samples for transmission electron microscopy (TEM) were prepared from the solutionized and oil-quenched material before and after mechanical testing. A 3 mm cylinder was first electro-discharge machined from the gage section of selected samples. Disks of $\sim 500$ $\mu \mathrm{m}$ thickness were then sliced from this $3 \mathrm{~mm}$ cylinder, mechanically ground to $\sim 130 \mu \mathrm{m}$ thickness, and electro-polished using a solution of $20 \% \mathrm{H} 2 \mathrm{SO} 4$ and $80 \%$ methanol (by volume) cooled to $-5{ }^{\circ} \mathrm{C}$ in a Struers Tenupol-5 twin-jet electropolisher. TEM images, diffraction patterns, and EDS data were collected at room temperature using a double tilt holder in a FEI Talos F200S microscope operating at $200 \mathrm{kV}$.

X-ray diffraction data collection and analysis were conducted on the s solution-treated alloy to identify the second phases and their approximate volume fraction. A Bruker D8 Advance diffractometer and a D8 Discover diffractometer (area detector) with $\mathrm{Cu} \mathrm{K} \alpha$ radiation and a 0.5 mm diameter collimator were used for the purpose. 


\subsection{Ex situ mechanical testing}

Ex situ mechanical tests were performed on an 810 MTS servohydraulic load frame using threaded, cylindrical dogbone samples $5.08 \mathrm{~mm}$ in diameter and $12.7 \mathrm{~mm}$ in gauge length. Samples were cyclically loaded in tension or compression at room temperature in straincontrolled conditions at a rate of $1 \times 10^{-4} \mathrm{sec}^{-1}$ using an axial extensometer. The testing sequence consisted of loading to selected stress levels in intervals of $500 \mathrm{MPa}$ with 10 load-unload cycles performed at each load level before reloading to the next stress level and repeating the cycling process. This was continued until failure (in tension) or when buckling loads (in compression) were reached.

\subsection{In situ neutron diffraction}

In situ neutron diffraction experiments were performed on the engineering materials diffractometer (VULCAN) at the Spallation Neutron Source (SNS), Oak Ridge National Laboratory. Neutron diffraction provides greater penetration depths (sampling volumes up to 1

$\mathrm{cm}^{3}$ ), as compared to surface measurements by X-ray diffraction, representing bulk behavior of polycrystalline samples and avoiding free surface stress effects. Furthermore, using VULCAN diffractometer, it is possible to follow the microstructural changes that occur while applying load, since diffraction patterns are simultaneously recorded. VULCAN is equipped with two position-sensitive detectors located on either side of the incident beam at $\pm 90^{\circ}$ at a distance of 2 $\mathrm{m}$ from the sample. The incident neutron beam impinges on the sample with the loading axis positioned at $45^{\circ}$ relative to the beam, with diffraction data collected simultaneously by the two detectors. An incident beam size of $3 \mathrm{~mm}$ x $4 \mathrm{~mm}$ at $1 \mathrm{MW}$ nominal source power was used for 
the diffraction measurements. The data was collected in high intensity mode using a chopper speed of $20 \mathrm{~Hz}$ resulting in a $d$-spacing range from 0.5 to $3.5 \AA$. A schematic of the diffraction setup and a detailed description of the instrument can be found elsewhere [20, 21].

In situ mechanical loading on VULCAN was performed at room temperature in straincontrolled conditions at a rate of $1 \times 10^{-4} \mathrm{sec}^{-1}$ using an axial clip-on extensometer. A threaded, cylindrical dogbone sample $(5.08 \mathrm{~mm}$ in diameter, $12.7 \mathrm{~mm}$ gauge $)$ was used for tension testing to $1.5 \mathrm{GPa}$, and a cylindrical sample $(6.75 \mathrm{~mm}$ in diameter, $15.24 \mathrm{~mm}$ long) was used for compression testing to -2.5 GPa. Each sample was loaded once, and neutron data was collected continuously and instantaneously during loading and unloading. In addition, at certain stress levels, high resolution data was also collected for 10 minute hold period.

\subsection{In situ synchrotron diffraction}

In situ synchrotron x-ray diffraction experiments were performed at the High Energy Materials Science (HEMS) beamline at the German high-brilliance synchrotron radiation storage ring PETRA III, at DESY, Hamburg. While neutron provides bulk diffraction information, in situ synchrotron $\mathrm{x}$-ray offers higher spatial resolution that can be beneficial when investigating multiphase and transforming materials such as SMAs. Measurements were conducted using a beam cross-section of $500 \times 500 \mu \mathrm{m}^{2}$ with $100 \mathrm{keV}$ photon energy $(\lambda=0.12427 \AA)$. DebyeScherrer diffraction rings were recorded using a MAR345 image plate detector (345 mm area diameter) with $100 \mu \mathrm{m}$ pixel size positioned at a sample-to-detector distance of $1.572 \mathrm{~m}$. A schematic of the diffraction setup and instrument details can be found in [22]. Cylindrical samples, $5 \mathrm{~mm}$ in diameter and $10 \mathrm{~mm}$ in length, were deformed in compression to $-750 \mathrm{MPa}$ in displacement control to match a calculated strain rate of $\sim 1 \times 10^{-4} \mathrm{sec}^{-1}$. 


\section{Results and discussion}

Representative microstructures of the 60NiTi in the as-extruded and solution-treated conditions are shown in Figs. 1-2. In both conditions, the matrix consisted of the B2 austenite phase with an average grain size of $\sim 50 \mu \mathrm{m}$, as shown by the optical micrograph of the $977{ }^{\circ} \mathrm{C}$ solution-treated and oil-quenched sample in Fig. 1. Comparative images of the as-extruded and solution-treated samples, taken at various magnifications to reveal the details of the underlying microstructures, are shown in Fig. 2. The as-extruded specimen (Fig. 2a) was essentially a twophase material with large micron size second phase particles, predominantly $\mathrm{Ni}_{3} \mathrm{Ti}$, distributed uniformly throughout the B2 matrix. Some TiC particles (black in Fig. 2a) that were introduced during the melting process via the graphite crucible were also observed in the microstructure of this and the solution-treated condition.

Solutionizing of the as-extruded material at $977{ }^{\circ} \mathrm{C}$ for 2.5 hours followed by oil quenching completely dissolved and suppressed the formation of large second phase particles on cooling as shown in Fig. 2(b0-2). Etching the sample (as in Fig. 1), however, suggested that there could be a fine second phase present in the B2 matrix in this condition. Thus, TEM was performed on the solution-treated material, which exposed a very high density of fine precipitates throughout the matrix (Fig. 3a). Selected area diffraction pattern (SADP) clearly revealed the characteristic $1 / 7\{312\}_{\mathrm{B} 2}$ spots for the $\mathrm{Ni}_{4} \mathrm{Ti}_{3}$ phase in the $\langle 111\rangle_{\mathrm{B} 2}$ zone axis [23]. The precipitates were coherent with the matrix and had an average size of $\sim 70 \mathrm{~nm}$. The neutron diffraction spectra (Fig. 4) confirmed that this material was composed of $\mathrm{B} 2$ austenite and $\mathrm{Ni}_{4} \mathrm{Ti}_{3}$ phase with an approximate precipitate volume fraction of $55 \pm 3 \%$ as determined by the Rietveld refinement of the neutron data and confirmed using conventional x-ray scans. Precipitation of such a large 
volume fraction of $\mathrm{Ni}_{4} \mathrm{Ti}_{3}$ phase, even on quenching, is common to these Ni-rich alloys [6], since nucleation of $\mathrm{Ni}_{4} \mathrm{Ti}_{3}$ precipitates from the B2 phase in very Ni-rich compositions can occur in milliseconds [18] making it nearly impossible to suppress in bulk samples using typical quenching processes. Therefore, while the material is referred to as "solution-treated" throughout this work, it should be noted that it is a precipitation strengthened material with a very high volume fraction of fine coherent precipitate phase. Finally, it should be noted that no martensite phase was detected in the samples prior to testing by any of these techniques.

The solution-treated material was isothermally deformed at room temperature in both tension and compression as shown in Fig. 5. For the tension case, the specimen was cyclically loadedunloaded 10 times at stress levels of 500, 1000 and $1500 \mathrm{MPa}$, and failed on loading to the next higher stress level. Similarly, the compression experiment consisted of 10 load-unload cycles at stresses up to $-2500 \mathrm{MPa}$ in $-500 \mathrm{MPa}$ increments, noting that higher stresses resulted in buckling. The initial elastic moduli were 99 and $107 \mathrm{GPa}$ for tension and compression, respectively. The stress-strain response in compression resulted in a reversible, linear-elastic behavior at stress levels up to -2000 MPa. In tension, a change in slope is observed at about 500$600 \mathrm{MPa}$, which is not observed in compression even at higher stresses. But the behavior in this second region is still nearly linear elastic, with an extremely small hysteretic component. This type of phenomenon has been observed in cold drawn NiTi $[24,25]$, and to some extent in a strain-glass $\mathrm{Ni}_{43} \mathrm{Fe}_{18} \mathrm{Ga}_{27} \mathrm{Co}_{12}$ alloy [26]. In these cases, it was reported that such phenomena were due to the confined martensitic transformation due to the small grain size [24] or the growth of nano-scale martensite in the strain glass alloys [26]. However, the 60NiTi alloy under investigation is neither a strain glass nor a fine grain size material; it is a polycrystalline material with relatively large grain size of $\sim 50 \mu \mathrm{m}$. 
In addition to the narrow hysteresis, the stress-strain curves of Fig. 5 show a high yield strength and large recoverable strains of $2.2 \%$ in tension and $2.5 \%$ in compression with a minor $(<0.1 \%)$ accumulation of residual strain that ensued on the very first cycle to $-2500 \mathrm{MPa}$ (in compression only), presumably due to the onset of plastic deformation at this high stress level. It is still unclear what causes the extended inelastic deformation manifested by the changes in modulus (deviation from linearity) in tension and the associated minor hysteresis loop, which tend to suggest the occurrence of stress induced martensite (SIM) as would be the case in a typical superelastic shape memory alloy.

To help understand this behavior, tension and compression tests were performed on the VULCAN diffractometer beamline at Oak Ridge National Laboratory. Neutron data was collected on loading and unloading to $1.5 \mathrm{GPa}$ in tension and -2.5 GPa in compression for one load-unload cycle only. The actual tensile and compressive stress-strain response is shown in Fig. 6 and the corresponding neutron data for both diffracting lattice planes perpendicular and parallel to the loading axis is included in Fig. 7. The lattice planes perpendicular to the loading direction represent the axial strains, while the lattice planes parallel to the loading direction represent the radial strains due to Poisson's effect. It is evident from these contour plots that most peaks shift on loading and some peaks change in intensity. While d-spacing shifts indicate the evolution of lattice strains, the intensity variations suggest that an inelastic mechanism, possibly SIM, twinning, or plasticity, is in effect, which causes intensities of some planes to increase at the expense of others.

Similar data was also collected in compression from the synchrotron source at DESY (Fig. 8); however, loading was restricted to a maximum stress of $-750 \mathrm{MPa}$ due to the equipment/geometry limitation. Nonetheless, similar observations were made regarding the 
macroscopic reversibility, and the microstructural features related to lattice shifts and intensity variations.

Based on the data presented this far, it is reasonable to rule out plasticity as a major contributing factor to the peak intensity changes, since a complete reversibility is obtained both mechanically (Figs. 5 and 6) and microstructurally (Figs. 7 and 8). A more detailed examination of narrow sections of the neutron data, presented as normalized diffraction spectra, are shown in Fig. 9 for tension and in Fig. 10 for compression. For the tension test, a combination of the appearance of new peaks (Figs. 9b and 9d), and peak overlap (Fig. 9e) is an indication of the evolution of a new phase at high stress. This phase was indexed as monoclinic B19' martensite that is formed by the SIM mechanism. Some of the most noticeable martensite peaks that evolved due to stress, e.g. $(011)_{\mathrm{B} 19^{\prime}}$ and $(002)_{\mathrm{B} 19^{\prime}}$, are similar to those that appeared in stoichiometric binary NiTi under similar conditions [27]. Referring back to Fig. 6a, deviation from linearity in the tensile stressstrain curve was observed around $500 \mathrm{MPa}$. It is approximately at this stress level where a clear $(002)_{\mathrm{B} 19^{\prime}}$ martensite peak started to evolve as shown in Fig. 9d. Keeping in mind that the B2 matrix is heavily constrained by a high volume fraction of non-transforming precipitate phase [28], and the fact that near linear superelastic behavior was observed until 1.5 GPa with very small hysteresis (Fig. 6), it is reasonable to conclude that only a small volume fraction of the austenite matrix goes through a SIM transformation. This phase transformation observed in this alloy with a high volume fraction of nano-sized precipitates can be characterized by confined martensitic transformation. Such behavior is due to the heterogeneous stress field around the fine precipitates that promotes certain preferred variants of the martensite rather than all the selfaccommodated variants. 
In compression, no SIM was identified within the instrument detection limits, as shown in Fig. 10, even though the ultimate stress level was much higher. This is consistent with the compressive stress-strain response of Fig. 6b, which exhibited a predominantly linear behavior up to $2.4 \mathrm{GPa}$, after which a slight deviation from linearity occurred. Consequently, deformation is governed by the elastic response of the precipitation-strengthened matrix until yielding occurs.

Tension-compression asymmetry is also observed in this alloy as shown in Figs. 5 and 6. This behavior is common in most SMAs [29] and other related materials such as gum metals [30, 31]. In the $\mathrm{Ti}-\mathrm{Nb}$ systems $[30,31]$, the asymmetry in the stress-strain response has been attributed to different phase transformation paths that occur during loading. In the NiTi-based systems however, the asymmetry involves many factors including elastic anisotropy, and operation of different amounts of various accommodative twinning (reversible) mechanisms, deformation twinning mechanisms (irreversible), and slip in order to accommodate the applied deformation on the material. It has been shown that there is no single change in deformation mechanisms, but instead differences in the amount of several deformation modes are responsible for deformation asymmetry in NiTi [29]. Given the high volume fraction of precipitate phase in the current alloy, it was possible to suppress slip in both tension and compression. Thus, the observed asymmetry is essentially due to the SIM that occurred in tension and not in compression, confirming the fact that the basic twin systems operating in tension and compression are different.

The reversibility of deformation for this alloy is further investigated by examining the lattice strains exhibited by both phases. The lattice strains associated with various planes of the austenite and $\mathrm{Ni}_{4} \mathrm{Ti}_{3}$ phase are plotted as a function of applied load in Fig. 11 and Fig. 12 for 
tension and compression, respectively. As previously mentioned, the lattice planes perpendicular to the loading direction represent the axial strains, while the lattice planes parallel to the loading direction represent the radial strains or Poisson's effects (i.e., negative strains). For the tension test, the strain partitioning is typical of anisotropic B2 austenite phase where the $\{111\}_{\mathrm{B} 2} /$ $\{220\}_{\mathrm{B} 2}$ are the stiffest reflections while the $\{100\}_{\mathrm{B} 2}$ families are the most elastically compliant reflections [32]. Concomitant with the macroscopic tensile data of Fig. 6, the lattice strain response of the $\{100\}_{\text {B2 }}$ family of planes exhibited a non-linear behavior (see Figs. 11a, 11c) also captured predominantly by the $(2 \overline{1} \overline{1})_{\mathrm{Ni}_{4} \mathrm{Ti}_{3}}$ planes of the precipitate phase as shown in Fig. $11 \mathrm{~b}$. This is indicative of the occurrence of a secondary mechanism (SIM in this case), which deflates the diffraction elastic constants. Nonetheless, the reversibility of the lattice strains is maintained as shown by the unloading segments of the lattice strains.

For the compression case (Fig. 12), the B2 reflections were mostly linear and less anisotropic in nature when compared to tension data. This is somewhat expected since no SIM was observed and the response corresponds predominantly to the elastic deformation of the material. However, it is noted that some of the $\mathrm{Ni}_{4} \mathrm{Ti}_{3}$ orientations such as $(2 \overline{1} 0)_{\mathrm{Ni}_{4} \mathrm{Ti}_{3}}$ and $(2 \overline{3} \overline{2})_{\mathrm{Ni}_{4} \mathrm{Ti}_{3}}$ change in compliance with loading as shown in Figs. $12 \mathrm{~b}$ and $12 \mathrm{~d}$. Although there is no SIM to account for this behavior, it is possible that growth or repartitioning of the $\mathrm{Ni}_{4} \mathrm{Ti}_{3}$ precipitates occur. It is also noted that small residual strains are observed in the $\mathrm{Ni}_{4} \mathrm{Ti}_{3}$ orientations and in the $\mathrm{B} 2$ phase as shown by the unloading curves of Fig. 12 .

Succeeding analyses were carried out to investigate the occurrence of SIM and any other microstructural changes that may have occurred during testing. The fractured tensile specimen, from which the data in Fig. 5a was generated, which had been cyclically loaded-unloaded 10 times each at stress levels of 500, 1000, and $1500 \mathrm{MPa}$ until it failed on loading at $1600 \mathrm{MPa}$, 
was selected for this purpose. TEM samples were prepared from the gauge section close to the fracture surface in an attempt to observe any locked in martensite that could have been retained after fracture and any other microstructural changes. The resulting microstructure, shown in Fig. 13a-c, was very different from the original solution-treated and quenched condition (Fig. 3a). The microstructure no longer consisted of uniformly dispersed fine $(\sim 70 \mathrm{~nm}) \mathrm{Ni}_{4} \mathrm{Ti}_{3}$ precipitates, but instead the $\mathrm{Ni}_{4} \mathrm{Ti}_{3}$ phase appeared to undergo considerable directional growth and coalescence. Some variants of $\mathrm{Ni}_{4} \mathrm{Ti}_{3}$ phase had grown preferentially until they were as large as $300 \mathrm{~nm}$ (Fig. 13b, c). These precipitates were confirmed to be the $\mathrm{Ni}_{4} \mathrm{Ti}_{3}$ phase and a typical SADP from two sets of precipitates taken along the $\langle 112\rangle_{\mathrm{B} 2}$ zone axis is shown in Fig. $13 \mathrm{~d}$. Similar coarsening of the $\mathrm{Ni}_{4} \mathrm{Ti}_{3}$ phase was also observed in the compression tested sample cycled 50 times from -500 to $-2500 \mathrm{MPa}$. This is shown in Fig. 13e-f.

In the tension tested sample, large micron size particles having equiaxed or long plate like morphologies (Fig. 14a, b respectively) and surrounded by precipitate free zones were also observed at the grain boundaries and within grains. These were identified as $\mathrm{Ni}_{3} \mathrm{Ti}$ phase via EDS (Fig. 14c) and SADP (Fig. 14d) analyses. The $\mathrm{Ni}_{3} \mathrm{Ti}$ phase was not present in the solutiontreated and quenched condition prior to testing but apparently nucleated and grew during room temperature cyclic tensile testing. Stress-induced martensite was not detected by TEM and therefore not retained in the microstructure after failure (in the unloaded condition). However, plastic deformation in the form of twins and dislocations were clearly visible, especially in the $\mathrm{Ni}_{3} \mathrm{Ti}$ phase, as shown in Fig. 14(b,e,f). In the compression tested sample, the $\mathrm{Ni}_{3} \mathrm{Ti}$ phase was not observed.

Consequently, the bulk microstructures of the gauge sections from the same tensile and compression tested samples were examined in the SEM to assess the prevalence and distribution 
of $\mathrm{Ni}_{3} \mathrm{Ti}$ formation during cyclic room-temperature testing. These microstructures are shown in Fig. 15b and Fig. 15d, respectively, and for comparison the original solution-treated and quenched pre-tested bulk microstructure at the same magnification is shown in Fig. 15a. This comparison clearly indicates that in the tension tested sample a considerable amount of $\mathrm{Ni}_{3} \mathrm{Ti}$ phase nucleated and grew primarily at the grain boundaries and occasionally within grains during testing (Fig. 15b).

At this point, the one cycle tension tested sample (from Fig. 6a) that was studied in the VULCAN beamline was also examined in the SEM and it was found that $\mathrm{Ni}_{3} \mathrm{Ti}$ nucleation is initiated within the first loading cycle itself, as shown in Fig. 15c. Thus, it is clear from Figs. 1315 , that room temperature tensile testing to $500-1500 \mathrm{MPa}$ stress results in preferential growth of the $\mathrm{Ni}_{4} \mathrm{Ti}_{3}$ phase in tension and compression and in addition nucleation and growth of the equilibrium $\mathrm{Ni}_{3} \mathrm{Ti}$ phase in tension. It is noted that due to the low volume fraction of the $\mathrm{Ni}_{3} \mathrm{Ti}$ phase in this condition (one cycle only - Fig. $15 \mathrm{c}$ ), the $\mathrm{Ni}_{3} \mathrm{Ti}$ peaks were not observed in the diffraction spectra shown in Fig. 9.

This large and apparently very ductile $\mathrm{Ni}_{3}$ Ti phase is likely the cause of premature failure in tension-tested samples. In contrast, the bulk microstructure of the cyclically-tested compression sample within (500-2500) MPa stresses did not show any $\mathrm{Ni}_{3} \mathrm{Ti}$ phase (Fig. 15d), and looked very similar to that of the original solution-treated and quenched material in that regard,, though at a finer scale, coarsening of the $\mathrm{Ni}_{4} \mathrm{Ti}_{3}$ phase did occur.

Based on the neutron diffraction data from the compression tested sample, there was broadening observed in some peaks as shown in Figs. 9 and 10. The peak breadth evolution, represented by full width half maximum (FWHM), are shown in Fig. 16 for several B2 and $\mathrm{Ni}_{4} \mathrm{Ti}_{3}$ reflections as a function of stress during loading and unloading. During tensile 
deformation (Fig. 16a-b), the austenite phase, particularly the $\{100\}_{\mathrm{B} 2}$ orientations are shown to broaden with applied load, but the process is reversible once the load is removed. This is consistent with the formation of reversible SIM within the B2 matrix. On the other hand, compressive deformation showed no SIM, but broadening of both the $\mathrm{B} 2$ and $\mathrm{Ni}_{4} \mathrm{Ti}_{3}$ phases was apparent. Both $(2 \overline{1} 0)_{\mathrm{Ni}_{4} \mathrm{Ti}_{3}}$ and $(1 \overline{2} \overline{1})_{\mathrm{Ni}_{4} \mathrm{Ti}_{3}}$ orientations exhibited the most broadening, with residuals on unloading within the data scatter. This is also consistent with the residual lattice strains that were observed in Fig. 12. It is not clear what causes the broadening on compressive loading, but it could be due to small amounts of SIM that were below the detection limit. At such high stress levels, it is not improbable for the formation of very small amounts of stress-induced martensite, but at levels below the detection limit of the equipment (on the order of 3-5 vol.\%). This would be consistent with the very narrow hysteresis observed at very high stress levels in Fig. 5. It is also possible that at such high stresses the $\mathrm{Ni}_{4} \mathrm{Ti}_{3}$ phase could be plastically yielding. Additional studies are in progress in order to rationalize and better understand these observations and the basic differences in tension and compression behavior.

Precipitation of second phases from a supersaturated solution is a technique that has been used for ages to enhance the strength of materials. In Ni-rich NiTi shape memory alloys, precipitation of fine Ni-rich $\mathrm{Ni}_{4} \mathrm{Ti}_{3}$ metastable phase not only increases the strength but also raises the transformation temperature by decreasing the Ni content of the matrix and moving the matrix composition towards stoichiometry. The unit cell of the $\mathrm{Ni}_{4} \mathrm{Ti}_{3}$ phase is rhombohedral $(\mathrm{R} \overline{3})$ with $\mathrm{a}=0.661 \mathrm{~nm}$ and $\alpha=113.65^{\circ}$, and it nucleates on $\{111\}_{\mathrm{B} 2}$ matrix $(\mathrm{a}=0.301 \mathrm{~nm}$, Pm3m) planes as oval/lens shape precipitates with $(111) \mathrm{Ni}_{4} \mathrm{Ti}_{3} \|\{111\}_{\mathrm{B} 2}$ [33]. There are 8 variants of the $\mathrm{Ni}_{4} \mathrm{Ti}_{3}$ phase, with 2 variants nucleating on the same $\{111\}_{\mathrm{B} 2}$ plane. The lattice mismatch between the coherent $\mathrm{Ni}_{4} \mathrm{Ti}_{3}$ precipitate and the $\mathrm{B} 2$ matrix results in a coherent strain in the 
matrix, which is maximum perpendicular to the precipitate [34]. Under stress-free conditions, these variants nucleate and grow such that a self-accommodative distribution is achieved to minimize the total strain energy of the system. But if an external stress is applied, the resulting local strain becomes different for dissimilar variants, thus changing the strain energy barrier to differently oriented variants causing selective variant growth of the $\mathrm{Ni}_{4} \mathrm{Ti}_{3}$ and nucleation of other more thermodynamically stable phases $[34,35]$. Thus, preferential growth and coarsening of the $\mathrm{Ni}_{4} \mathrm{Ti}_{3}$ metastable phase after tensile and compression testing, and precipitation and growth of the stable equilibrium $\mathrm{Ni}_{3} \mathrm{Ti}$ phase after tensile testing are the result of the externally applied stress. It is anticipated that $\mathrm{Ni}_{3} \mathrm{Ti}$ phase formed either by decomposition of the $\mathrm{Ni}_{4} \mathrm{Ti}_{3}$ phase or nucleated at the martensite twin regions that formed under load.

It is interesting to note that in spite of the changes in microstructure during cyclic testing, the alloy is still capable of withstanding high stresses $(\sim 1.5 \mathrm{GPa}$ in tension and $\sim 2.5 \mathrm{GPa}$ in compression) and recover completely with no residual strain (Fig. 5). Regardless, coarsening of the $\mathrm{Ni}_{4} \mathrm{Ti}_{3}$ phase and nucleation of large micron size $\mathrm{Ni}_{3} \mathrm{Ti}$ precipitates at grain boundaries and within grains are not desirable and likely to lead to a loss in strength, as well as become sources for fatigue, wear failure, and localized corrosion. This is an important issue that needs attention when considering this Ni-rich 60NiTi for bearing and other tribological systems as a promising material for aerospace components and mechanism applications $[14,36]$.These materials offer a unique combination of properties such as high hardness, low stiffness, corrosion resistance, high tolerance for lubricants, and reduced density not found in other bearing materials. While first proposed for such applications by Buehler [3] nearly five decades ago it was not until very recently with advances in materials processing that it was possible to fabricate aerospace quality balls and other bearing components [37] thus proving out the advantages of these materials. But 
only now has emphasis focused on understanding the actual deformation and fracture related mechanisms in these alloys $[6,14]$. The current work is the first detailed attempt to understand the deformation behavior of one of these alloys. The work confirms the prior advantages claimed for these materials, namely a low modulus, relatively extensive elastic strain capability, and high strength. Superelastic behavior, which can possibly lead to enhanced damage tolerance, was also confirmed in tension but not in compression in the current condition. This unusual anisotropic behavior will be the focus of further studies. However, one disconcerting result was the observation of stress-induced $\mathrm{Ni}_{3} \mathrm{Ti}$ formation at room temperature in tension and coarsening of the $\mathrm{Ni}_{4} \mathrm{Ti}_{3}$ phase in both tension and compression. While it is not clear how this will affect bearing fatigue life where loading is predominantly in compression, this would be a definite concern for gears and other applications. Thus, an effort to reduce the coarsening and decomposition of the strengthening $\mathrm{Ni}_{4} \mathrm{Ti}_{3}$ phase via ternary elemental addition and modified heat treatments is underway to mitigate this issue. Recent work on NiTiHf alloys by Hornbuckle et al. [18] has shown that Hf additions to Ni-rich NiTi result in precipitation of H-phase within the $\mathrm{B} 2$ channels between the $\mathrm{Ni}_{4} \mathrm{Ti}_{3}$ phase precipitates. These H-phase precipitates prevent coarsening of the $\mathrm{Ni}_{4} \mathrm{Ti}_{3}$ phase and decomposition to $\mathrm{Ni}_{3} \mathrm{Ti}$ under normal thermal conditions and may be effective against similar changes due to stress. This possible alloy design solution is currently being investigated, and mechanical loading experiments are underway.

\section{Conclusion}

The deformation behavior of the Ni-rich intermetallic alloy $\mathrm{Ni}_{55} \mathrm{Ti}_{45}$ (at.\%) (60NiTi wt.\%) was investigated under isothermal tensile and compressive loading to 1.5 and $-2.5 \mathrm{GPa}$, respectively. The relationship between the macroscopic response and the microstructural 
evolution was examined using in situ neutron and synchrotron diffraction, and supplemented by ex situ scanning and transmission electron microscopy. From the results obtained, several conclusions can be made:

a. The solution-treated and quenched $60 \mathrm{NiTi}$ (wt. \%) material was composed of a B2 cubic matrix and a high volume fraction of finely dispersed $\mathrm{Ni}_{4} \mathrm{Ti}_{3}$ rhombohedral, precipitate phase that provides significant strengthening. The precipitates were on the order of $70 \mathrm{~nm}$ with an approximate volume fraction of $55 \pm 3 \%$ as determined by neutron Rietveld refinement and conventional x-ray measurements.

b. The non-linear behavior observed during tensile loading was attributed to stress-induced martensite (SIM) that occurs within the B2 phase to accommodate the applied stress. The strain was fully reversible and no plastic deformation occurred within the austenite phase under the tested stress and cycle values.

c. Compressive loading up to $-2.5 \mathrm{GPa}$ resulted in no detectable SIM and the response was fully reversible. At higher stresses buckling occurred resulting in permanent plastic deformation.

d. Preferential growth and coarsening of the $\mathrm{Ni}_{4} \mathrm{Ti}_{3}$ phase was observed after both tensile and compressive testing, while the precipitation and growth of the equilibrium $\mathrm{Ni}_{3} \mathrm{Ti}$ phase was observed only after tensile testing using TEM and SEM analyses.

\section{Acknowledgment}

Funding from the NASA (ARMD) Transformational Tools \& Technologies (TTT) project is gratefully acknowledged. This work has benefited from the use of the Spallation Neutron Source at Oak Ridge National Laboratory, which is funded by the Division of Scientific 
User Facilities, Office of Basic Energy Sciences, U.S. Department of Energy under Contract DEAC05- 00OR22725 with UT-Battelle, LLC. This work has also benefited from the use of the HEMS beamline at the German high-brilliance synchrotron radiation storage ring PETRA III on

DESY. The authors thank R.B. Rogers of NASA for x-ray measurements, and also thank G.S. Bigelow, S.A. Padula II and D.J. Gaydosh for helpful discussions. O. Benafan thanks B. Palmer (student intern from Dartmouth College) for help with neutron data analysis, and D.E. Nicholson for neutron experimental help.

\section{References}

[1] D. Brei, J. Luntz, J. Shaw, N.L. Johnson, A.L. Browne, P.W. Alexander, N.D. Mankame, General Motors and the University of Michigan smart materials and structures collaborative research laboratory, in: Proc. SPIE 6527, 2007, pp. 65270U-65212.

[2] K. Yamauchi, I. Ohkata, K. Tsuchiya, S. Miyazaki, Shape memory and superelastic alloys: technologies and applications, Woodhead Pub., 2011.

[3] W.J. Buehler, F.E. Wang, A summary of recent research on the nitinol alloys and their potential application in ocean engineering, Ocean Eng., 1 (1968) 105-120.

[4] C. Wojcik, Shape memory properties of nickel rich Ni-Ti alloys in: Pelton A., Duerig T. (Eds.) SMST-2003: Proc. Int. Conf. on Shape Memory and Superelastic Technologies (Pacific Grove, CA), pp 43-52, 2003.

[5] C. Wojcik, Aging effects in nickel rich NiTi alloys, in: M. Mertmann (Ed.) SMST-2004: Proc. Int. Conf. on Shape Memory and Superelastic Technologies (Baden-Baden, Germany), pp 229-36, 2004.

[6] C.B. Hornbuckle, X.X. Yu, R.D. Noebe, R. Martens, M.L. Weaver, G.B. Thompson, Hardening behavior and phase decomposition in very Ni-rich Nitinol alloys, Mater. Sci. Eng., A, 639 (2015) 336-344.

[7] K. Dehghani, A.A. Khamei, Hot deformation behavior of 60Nitinol (Ni60 wt\%-Ti40 wt\%) alloy: Experimental and computational studies, Mater. Sci. Eng., A, 527 (2010) 684-690.

[8] M.K. Stanford, Charpy Impact Energy and Microindentation Hardness of 60-NITINOL, NASA/TM-2012-216029, (2012).

[9] A.C. Stott, J.I. Brauer, A. Garg, S.V. Pepper, P.B. Abel, C. DellaCorte, R.D. Noebe, G. Glennon, E. Bylaska, D.A. Dixon, Bonding and Microstructural Stability in Ni55Ti45 Studied by Experimental and Theoretical Methods, J. Phys. Chem. C, 114 (2010) 19704-19713.

[10] D.J. Arbogast, R.T. Ruggeri, R.C. Bussom, Development of a 1/4-scale NiTinol actuator for reconfigurable structures, in, 2008, pp. 69300L-69312.

[11] D.J. Hartl, D.C. Lagoudas, F.T. Calkins, J.H. Mabe, Use of a Ni60Ti shape memory alloy for active jet engine chevron application: I. Thermomechanical characterization, Smart Mater. Struct., 19 (2010) 15020. 
[12] D.J. Hartl, J.T. Mooney, D.C. Lagoudas, F.T. Calkins, J.H. Mabe, Use of a Ni60Ti shape memory alloy for active jet engine chevron application: II. Experimentally validated numerical analysis, Smart Mater. Struct., 19 (2010) 015021.

[13] L.M. Gravatt, J.H. Mabe, F.T. Calkins, D.J. Hartl, Characterization of varied geometry shape memory alloy beams, in, 2010, pp. 76450U-76450U-76412.

[14] C. DellaCorte, M.K. Stanford, T.R. Jett, Rolling Contact Fatigue of Superelastic Intermetallic Materials (SIM) for Use as Resilient Corrosion Resistant Bearings, Tribol. Lett., 57 (2015) 26.

[15] G. Julien, Nitinol ice blades, US Patent 2005/0082773 A1, (2005).

[16] G. Julien, Shape memory parts of 60 nitinol, US Patent 7,005,018, (2008).

[17] S. Ingole, 60NiTi Alloy for Tribological and Biomedical Surface Engineering Applications, JOM, 65 (2013) 792-798.

[18] B.C. Hornbuckle, R.D. Noebe, G.B. Thompson, Influence of Hf Solute Additions on the Precipitation and Hardenability in Ni-rich NiTi Alloys, J. Alloys Compds, 640 (2015) 449-454.

[19] C. DellaCorte, L.E.M. III, J.S. Clifton, The Effect of Pre-Stressing on the Static Indentation Load Capacity of the Superelastic 60NiTi, NASA/TM-2013-216479, (2013).

[20] K. An, H. Skorpenske, A. Stoica, D. Ma, X.-L. Wang, E. Cakmak, First In Situ Lattice Strains Measurements Under Load at VULCAN, Metall. Mater. Trans. A, 42 (2011) 95-99.

[21] O. Benafan, S. A. Padula II, H. D. Skorpenske, K. An, R. Vaidyanathan, Design and implementation of a multiaxial loading capability during heating on an engineering neutron diffractometer, Rev. Sci. Instrum., 85 (2014) 103901.

[22] O. Benafan, A. Garg, R.D. Noebe, G.S. Bigelow, S.A. Padula II, D.J. Gaydosh, N. Schell, J.H. Mabe, R. Vaidyanathan, Mechanical and functional behavior of a Ni-rich $\mathrm{Ni}_{50.3} \mathrm{Ti}_{29.7} \mathrm{Hf}_{20}$ high temperature shape memory alloy, Intermetallics, 50 (2014) 94-107.

[23] T. Saburi, S. Nenno, T. Fukuda, Crystal Structure and Morphology of the Metastable Xphase in a Shape Memory Ti-Ni Alloys, J. Less-Common Met., 125 (1986) 157-166.

[24] Y.F. Zheng, B.M. Huang, J.X. Zhang, L.C. Zhao, The microstructure and linear superelasticity of cold-drawn TiNi alloy, Mater. Sci. Eng., A, 279 (2000) 25-35.

[25] A. Ahadi, Q. Sun, Stress hysteresis and temperature dependence of phase transition stress in nanostructured NiTi-Effects of grain size, Appl. Phys. Lett., 103 (2013) 021902.

[26] Q.H. Zhang, Z. Zhai, Z. H. Nie, S. Harjo, D. Y. Cong, M.G. Wang, J. Li, Y.D. Wang, In situ neutron diffraction study of anomalous super-elasticity in strain-glassy $\mathrm{Ni}_{43} \mathrm{Fe}_{18} \mathrm{Ga}_{27} \mathrm{Co}_{12}$ alloy, $\mathrm{J}$. Appl. Cryst., 48 (2015) 1183-1191.

[27] O. Benafan, R.D. Noebe, S.A. Padula II, A. Garg, B. Clausen, S.C. Vogel, R. Vaidyanathan, Temperature Dependent Deformation of B2 Austenite in a NiTi Shape Memory Alloy, Int. J. Plast., 51 (2013) 103-121.

[28] E. Akin, Effect of Aging Heat Treatments on $\mathrm{Ni}_{52} \mathrm{Ti}_{48}$ Shape Memory Alloy (Master's Thesis), in, Texas A\&M University, College Station, TX, 2010.

[29] A.P. Stebner, S.C. Vogel, R.D. Noebe, T. Sisneros, B. Clausen, D.W. Brown, A. Garg, L.C. Brinson, Micromechanical quantification of elastic, twinning, and slip strain partitioning exhibited by polycrystalline, monoclinic nickel-titanium during large uniaxial deformations measured via in-situ neutron diffraction, Journal of the Mechanics and Physics of Solid, 61 (2013) 2302-2330.

[30] J.P. Liu, Y.D. Wang, Y.L. Hao, H.L. Wang, Y. Wang, Z.H. Nie, R. Su, D. Wang, Y. Ren, Z.P. Lu, J.G. Wang, X.D. Hui, R. Yang, High-energy X-ray diffuse scattering studies on 
deformation-induced spatially confined martensitic transformations in multifunctional $\mathrm{Ti}-24 \mathrm{Nb}-$ 4Zr-8Sn alloy, Acta Materialia, 81 (2014) 476-486.

[31] J.-P. Liu, Y.-D. Wang, Y.-L. Hao, Y. Wang, Z.-H. Nie, D. Wang, Y. Ren, Z.-P. Lu, J. Wang, H. Wang, X. Hui, N. Lu, M.J. Kim, R. Yang, New intrinsic mechanism on gum-like superelasticity of multifunctional alloys, Scientific Reports, 3 (2013) 2156.

[32] A.A. Saleh, E.V. Pereloma, B. Clausen, D.W. Brown, C.N. Tomé, A.A. Gazder, Selfconsistent modelling of lattice strains during the in-situ tensile loading of twinning induced plasticity steel, Mater. Sci. Eng., A, 589 (2014) 66-75.

[33] M. Nishida, C.M. Wayman, R. Kainuma, T. Honma, Further Electron Microscopy Studies of the $\mathrm{Ti}_{11} \mathrm{Ni}_{14}$ phase in an aged Ti-52at\% Ni shape memory alloy, Scripta Metall., 20 (1986) 899904.

[34] D.Y. Li, L.Q. Chen, Selective variant growth of coherent $\mathrm{Ti}_{11} \mathrm{Ni}_{14}$ precipitate in a TiNi alloy under applied stress, Acta Mater., 45 (1997) 471-479.

[35] W. Hort, W.C. Johnson, Coarsening of precipitate clusters in stress gradients, scripta Mater., 34 (1996) 1015-1020.

[36] C. DellaCorte, R.D. Noebe, M.K. Stanford, S.A. Padula II, Resilient and Corrosion-Proof Rolling Element Bearings Made from Superelastic Ni-Ti Alloys for Aerospace Mechanism Applications, in: Y.R. Takeuchi, W.F. Mandler (Eds.) in Rolling Element Bearings, 9th Volume, STP 1542, West Conshohocken, PA, 2012, pp. 143-166.

[37] C. DellaCorte, W.A. Wozniak, Design and Manufacturing Considerations for Shockproof and Corrosion-Immune Superelastic Nickel-Titanium Bearings for a Space Station Application, NASA/TM-2012-216015, (2012). 


\section{Figures:}

Fig. 1. Optical micrograph of the solutionized 60NiTi alloy at room temperature providing an indication of the grain size and morphology.

Fig. 2. SEM microstructure of the undeformed 60NiTi alloy at room temperature. (a) as-extruded condition, and (b) solution-treated and oil quenched condition.

Fig. 3. TEM micrographs of the solution-treated $60 \mathrm{NiTi}$ alloy taken at room temperature showing (a) general microstructure with fine precipitates, and (b) selected area diffraction pattern (SADP) confirming the precipitates as rhombohedral $\mathrm{Ni}_{4} \mathrm{Ti}_{3}$ phase within the $\mathrm{B} 2$ matrix.

Fig. 4. Representative neutron diffraction patterns of the solution-treated 60NiTi alloy measured at room temperature before deformation. (a) Neutron diffraction pattern with diffracting lattice planes perpendicular to the loading axis. The tick-marks below the profile pattern indicate the B2 and $\mathrm{Ni}_{4} \mathrm{Ti}_{3}$ reflections used in the refinement. (b) Synchrotron X-ray area diffraction pattern (quarter of image plane) confirming the $\mathrm{B} 2$ and $\mathrm{Ni}_{4} \mathrm{Ti}_{3}$ phases. For clarity, only some rings are indicated here.

Fig. 5. Ex situ macroscopic stress-strain curves of the solution-treated 60NiTi alloy at room temperature. (a) Tensile responses in the absolute scale and (b) shifted for clarity. (d) Compressive responses in the absolute scale and (e) shifted for clarity. (c) and (f) indicate the cycle count and the transition to different stress levels.

Fig. 6. In situ macroscopic stress-strain curves of the solution-treated 60NiTi alloy at room temperature for (a) tension and (b) compression. Open symbols indicate positions along the stress-strain curves where in situ neutron diffraction measurements were performed. The dashed lines are extrapolation of the linear-elastic regions.

Fig. 7. The 2-D and 3-D in situ neutron diffraction contour results during loading and unloading in (a-b) tension and (c-d) compression. Both lattice planes perpendicular and parallel to loading direction are included.

Fig. 8. In situ synchrotron x-ray diffraction results during loading and unloading in compression. (a) Stress-displacement responses, (b) Debye-Scherrer diffraction rings at 0 and -750 MPa, and (c) 3-D contour plot of the integrated data on loading and unloading to $-750 \mathrm{MPa}$.

Fig. 9. Normalized diffraction spectra acquired during tensile loading and unloading. Reflections are from $(\mathrm{a}-\mathrm{e})$ lattice planes perpendicular and $(\mathrm{f}-\mathrm{j})$ lattice planes parallel to the loading direction.

Fig. 10. Normalized diffraction spectra acquired during compressive loading and unloading. Reflections are from (a-e) lattice planes perpendicular and $(f-j)$ lattice planes parallel to the loading direction. 
Fig. 11. Applied tensile stress vs. lattice strains measured using neutron diffraction for several B2 and $\mathrm{Ni}_{4} \mathrm{Ti}_{3}$ reflections (a-b) perpendicular and (c-d) parallel to the loading direction. The data included both loading and unloading strains.

Fig. 12. Applied compression stress vs. lattice strains measured using neutron diffraction for several $\mathrm{B} 2$ austenite and $\mathrm{Ni}_{4} \mathrm{Ti}_{3}$ reflections (a-b) perpendicular and (c-d) parallel to the loading direction. The data included both loading and unloading strains.

Fig. 13. TEM microstructure of the post-cycled and fractured 60NiTi (a-c) tensile sample near the fractured end / and (e,f) compression sample showing (a-c/e,f) directional growth and coalescence of the $\mathrm{Ni}_{4} \mathrm{Ti}_{3}$ precipitates. (d) SADP from two sets of $\mathrm{Ni}_{4} \mathrm{Ti}_{3}$ precipitates in a $\langle 112\rangle_{\mathrm{B} 2}$ zone axis. The loading direction is perpendicular to the image.

Fig. 14. TEM microstructure of the post-cycled and fractured tensile 60NiTi sample showing large micron size $\mathrm{Ni}_{3} \mathrm{Ti}$ phase particles that were not observed in the solution-treated and quenched condition before testing.

Fig. 15. SEM images of the 60NiTi alloy in (a) the solution-treated condition before testing, (b) after the $30^{\text {th }}$ tensile loading cycle from Fig. 5a, (c) after the first tensile loading from Fig. 6a, and (d) after the $50^{\text {th }}$ compressive loading from Fig. 5 b.

Fig. 16. Full-width of half-maximum (peak broadening) of the $\mathrm{B} 2$ austenite and $\mathrm{Ni}_{4} \mathrm{Ti}_{3}$ reflections $(\mathrm{a}-\mathrm{c})$ perpendicular and $(\mathrm{b}-\mathrm{d})$ parallel to the loading direction. 


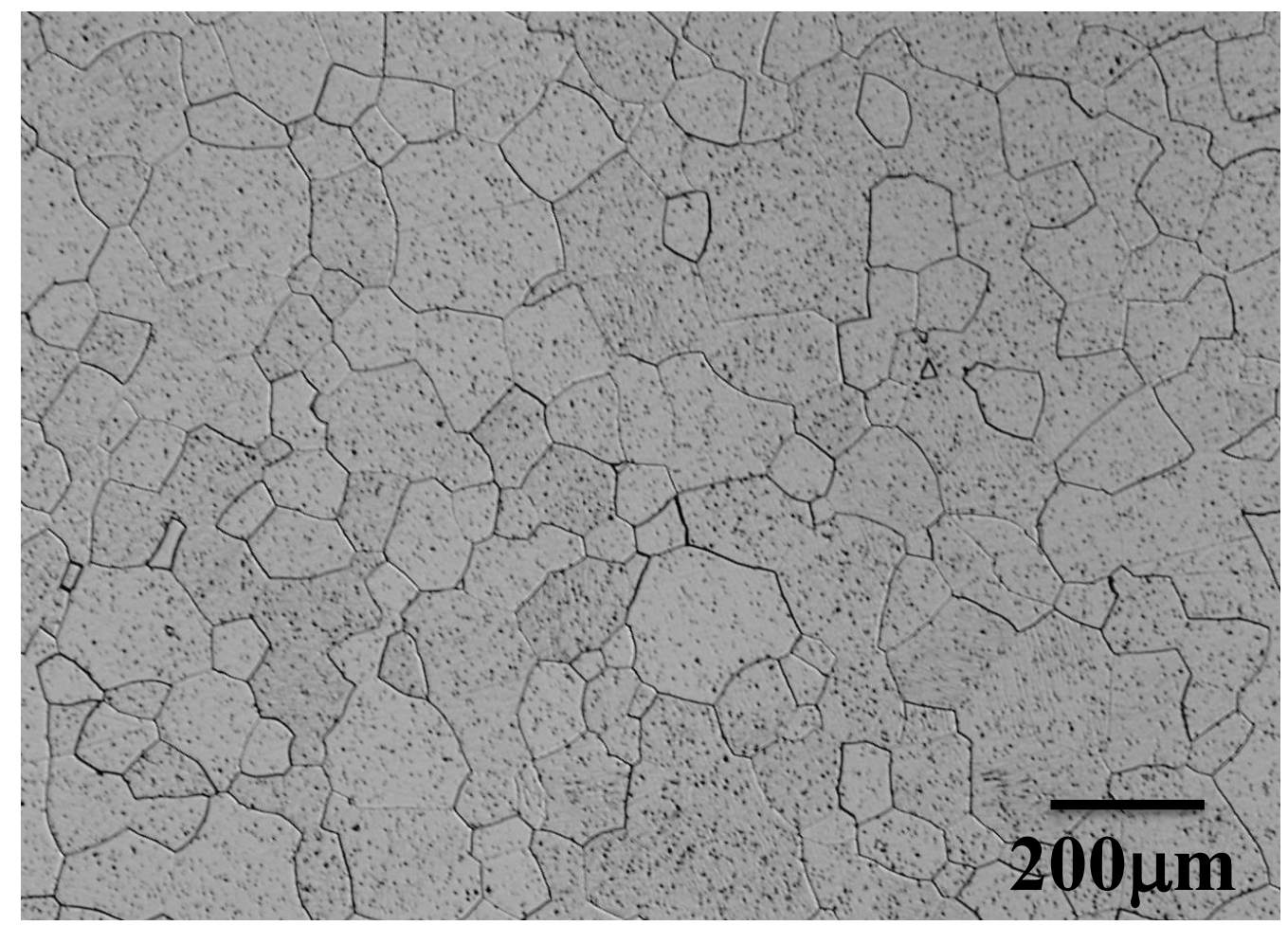

Fig. 1 


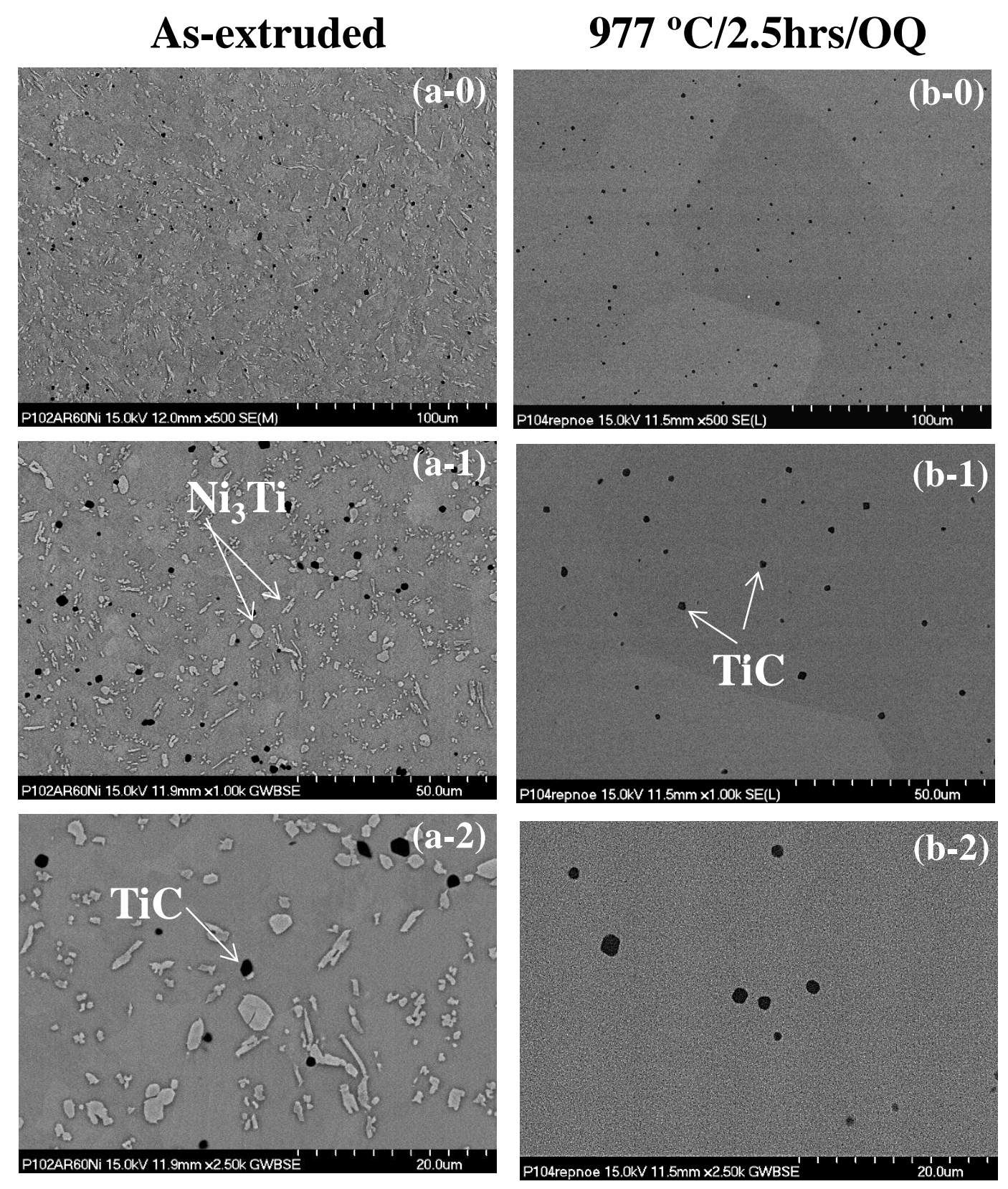

Fig. 2 

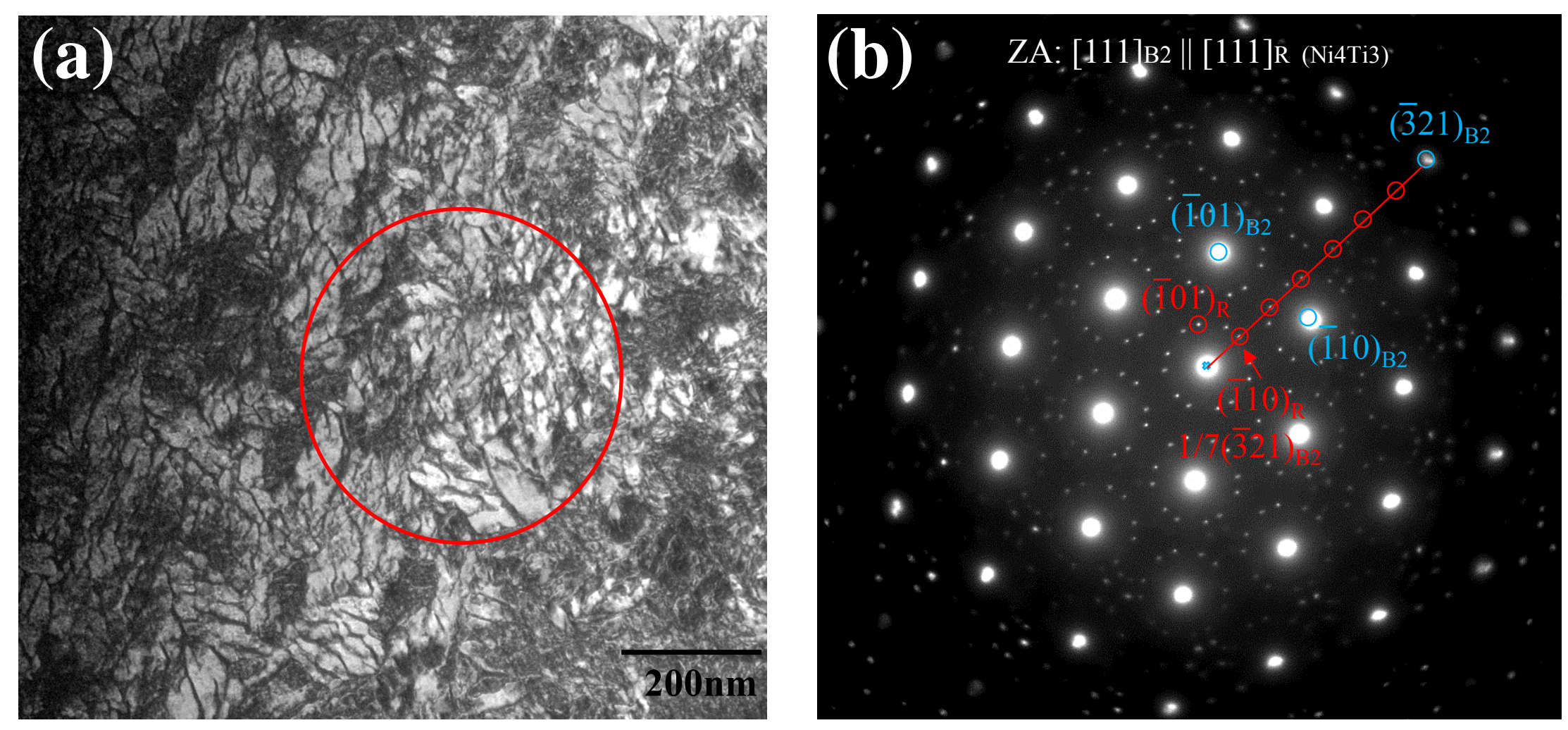

Fig. 3 

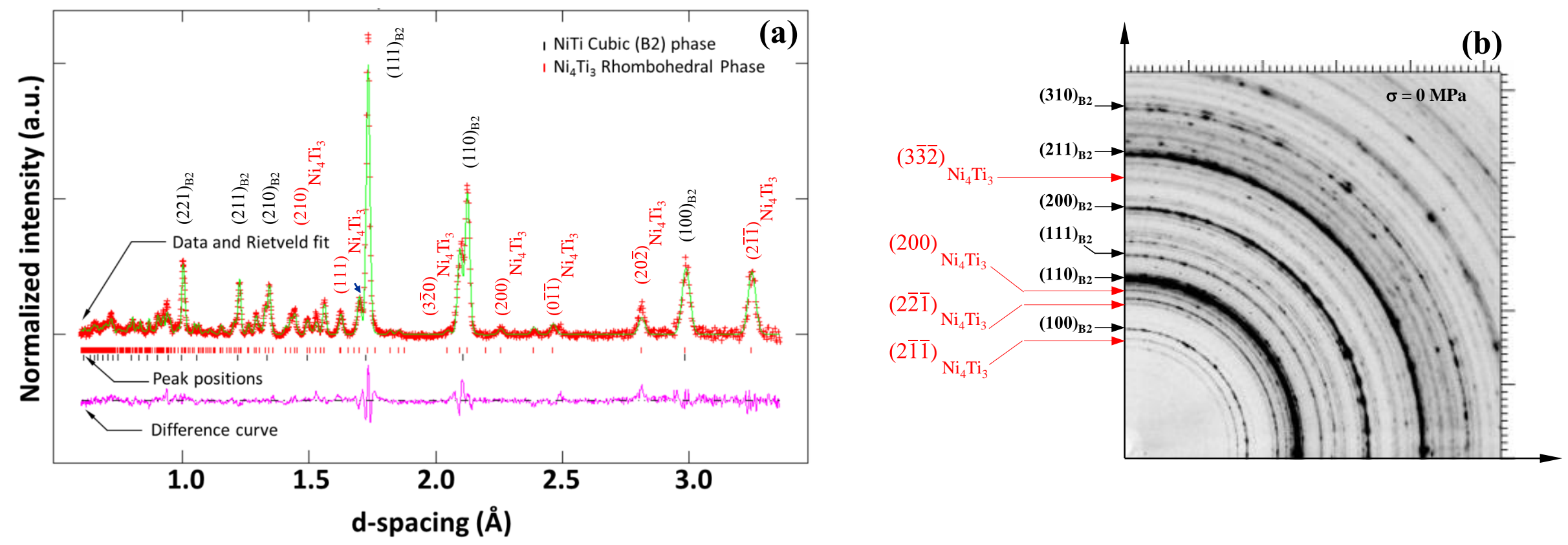

Fig. 4 

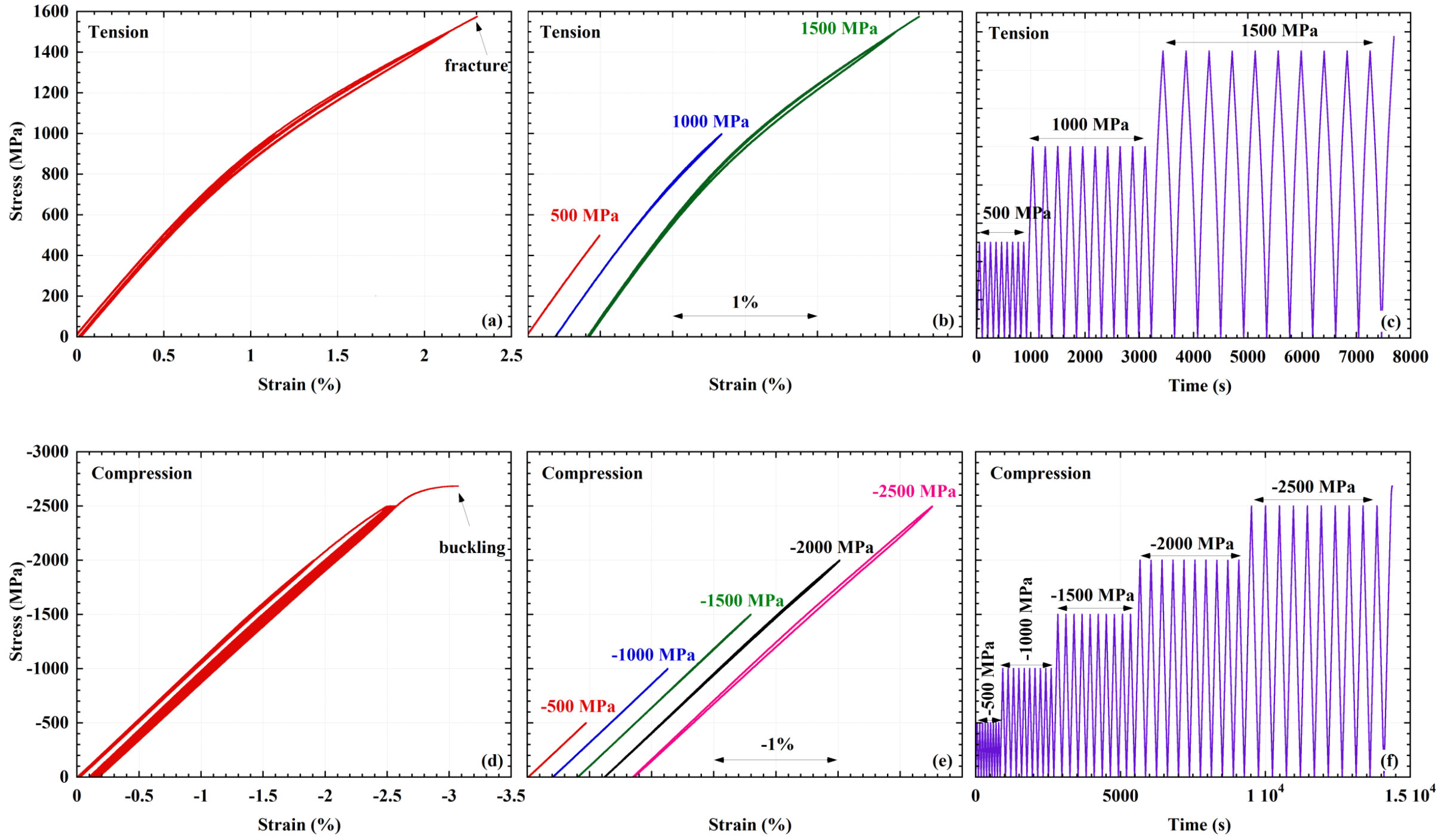

\section{Fig. 5}



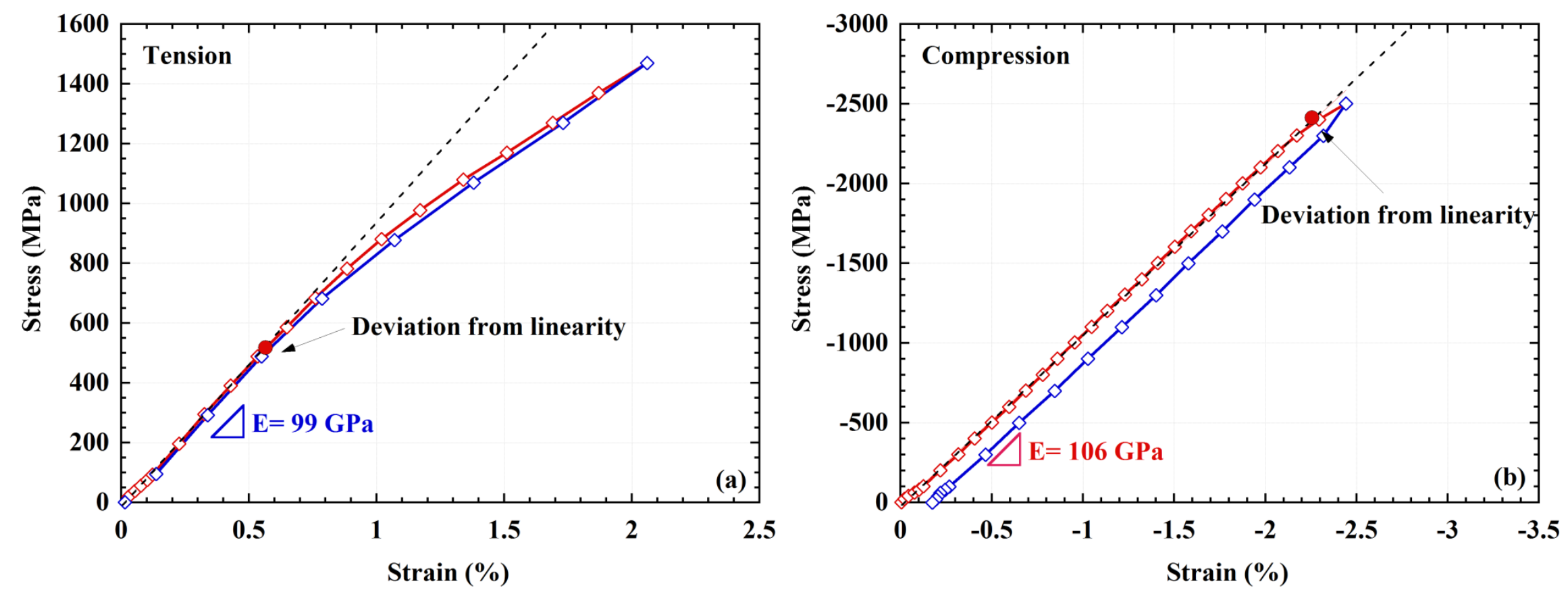

Fig. 6 

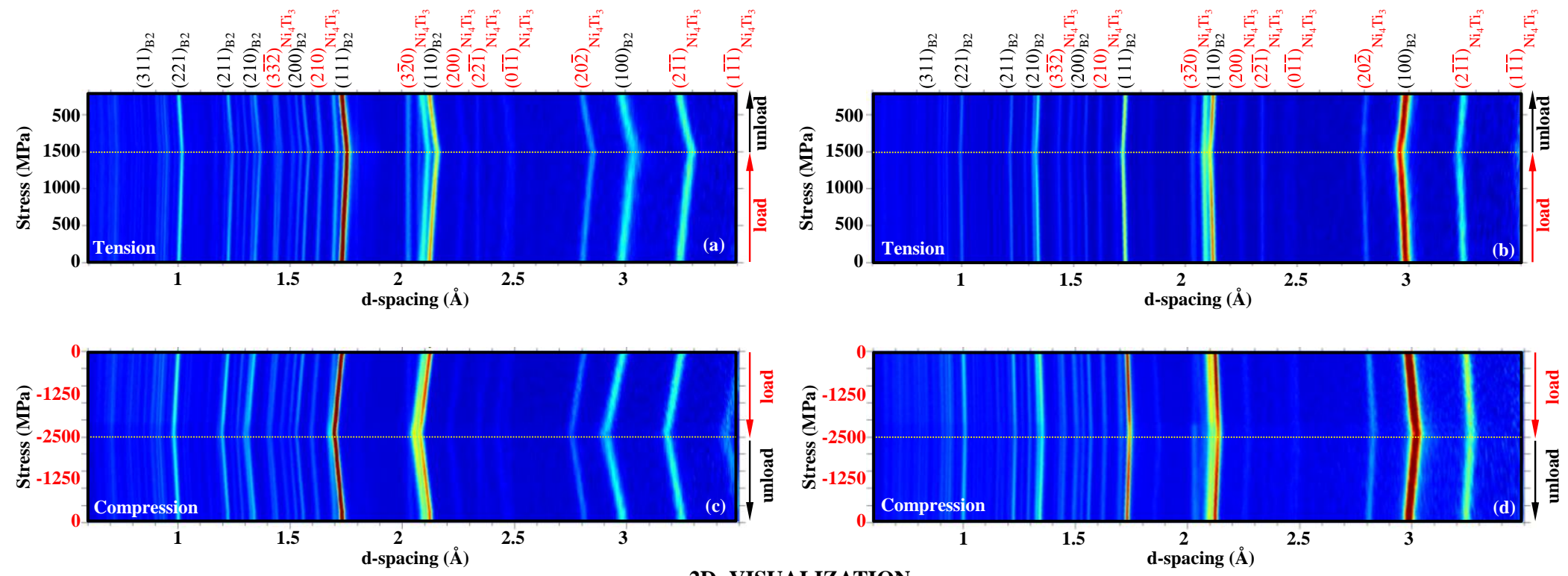

2D- VISUALIZATION

Lattice planes $\perp$ to loading direction
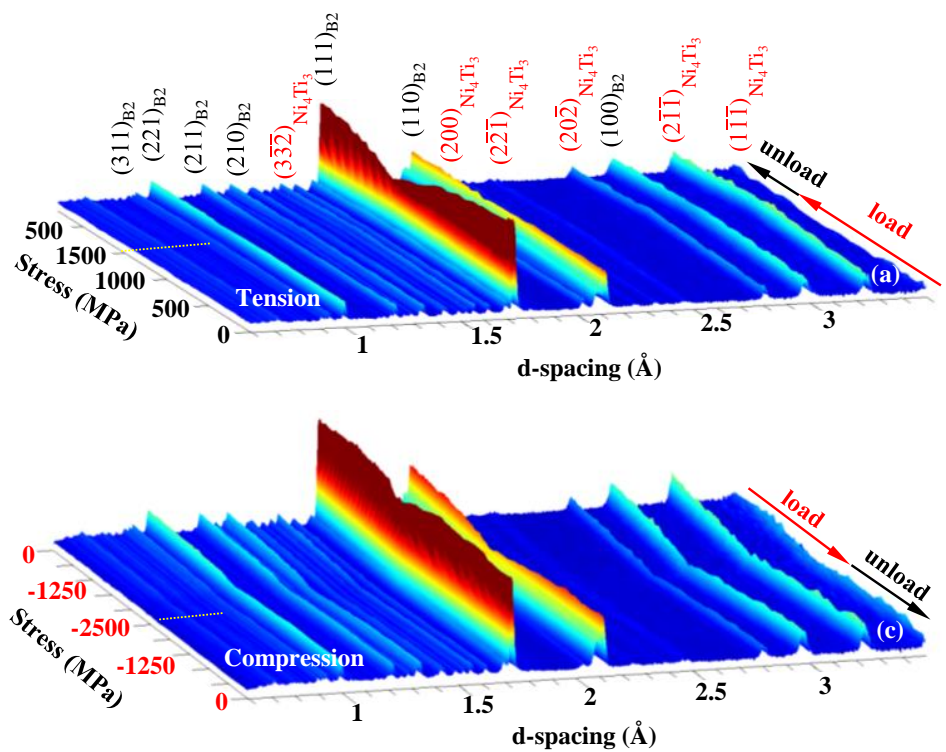

Lattice planes // to loading direction
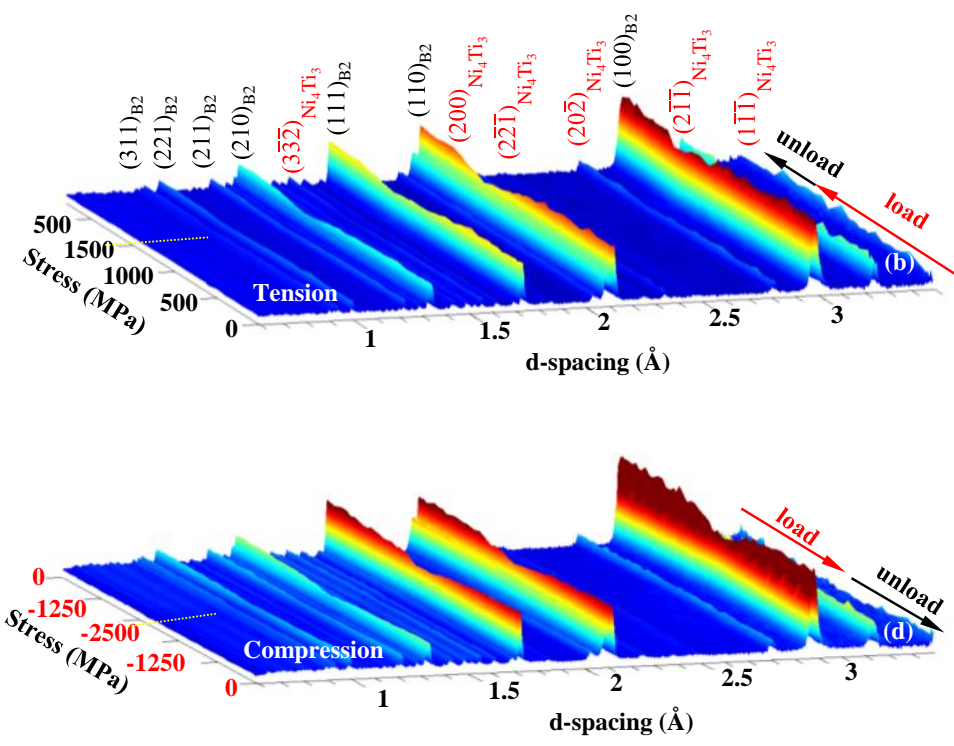

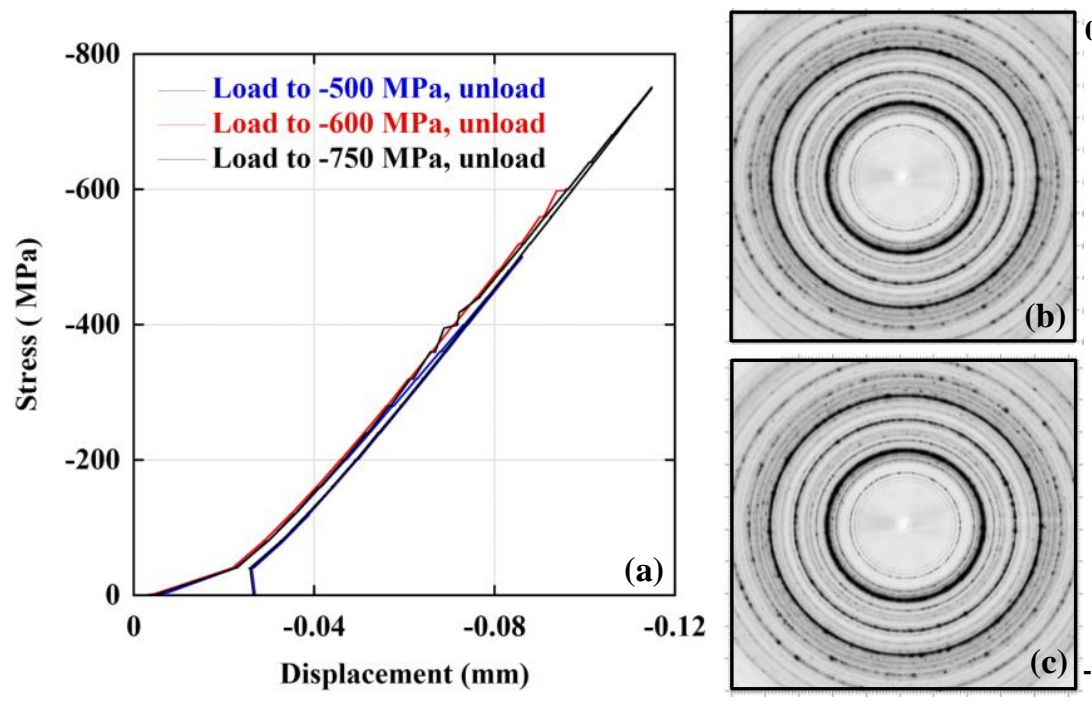

0 MPa

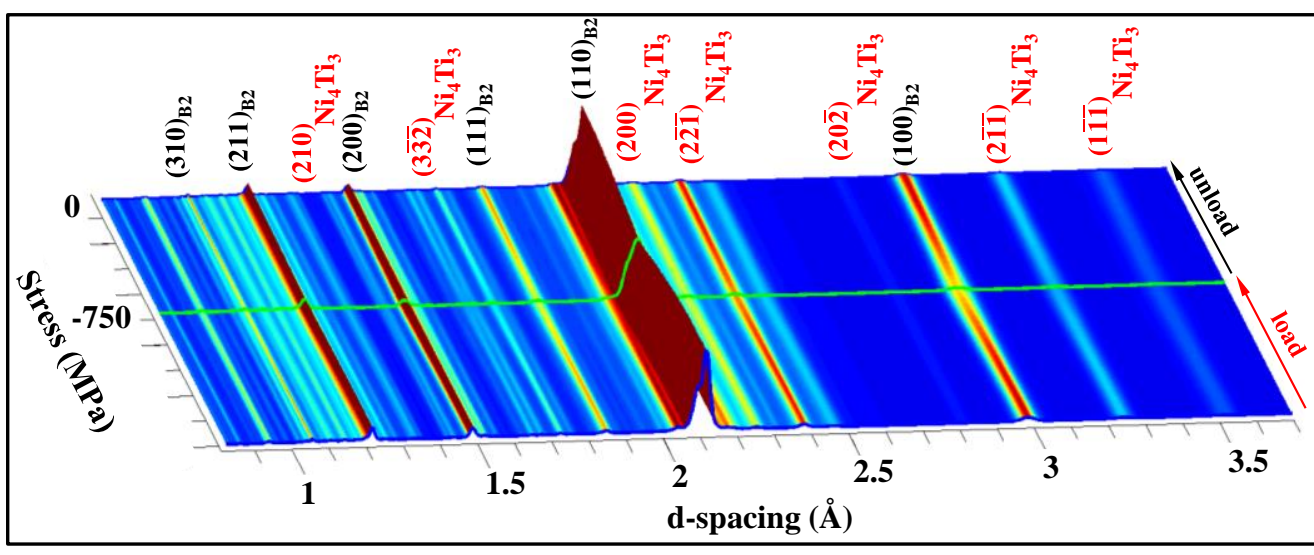

Fig. 8 
Lattice planes $\perp$ to loading direction
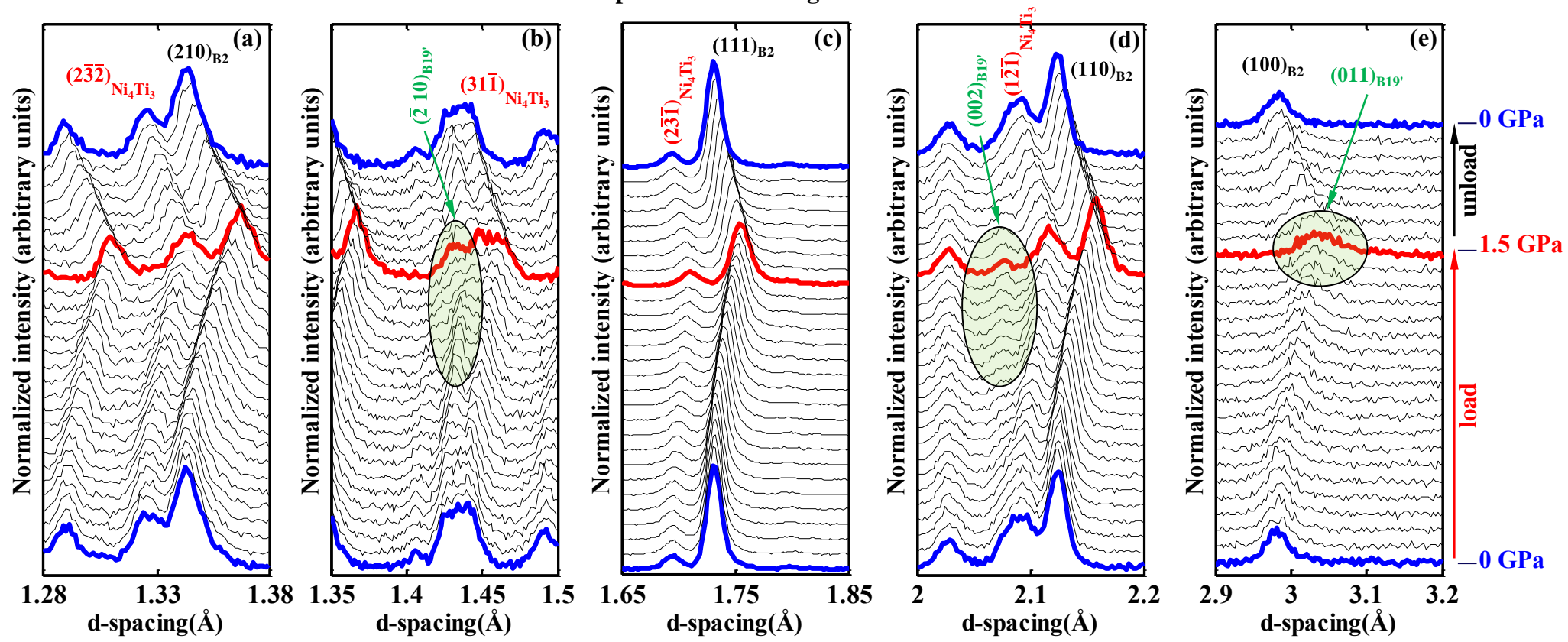

Lattice planes // to loading direction
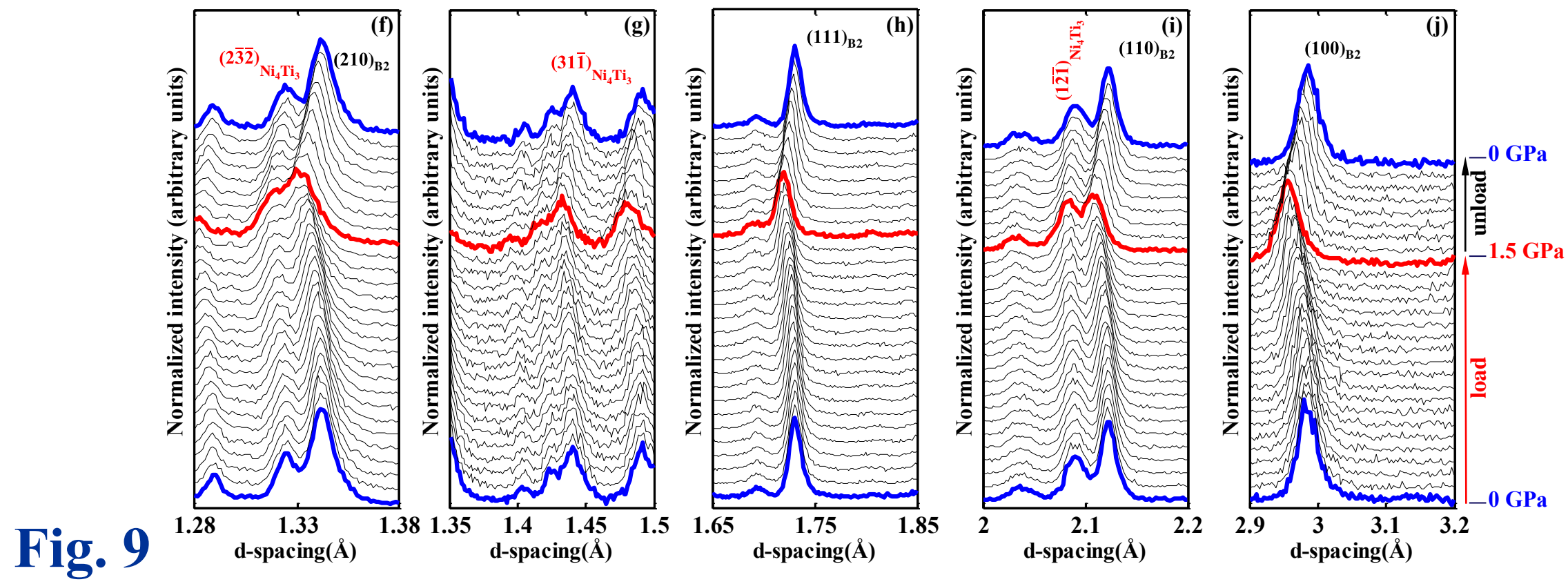
Lattice planes $\perp$ to loading direction
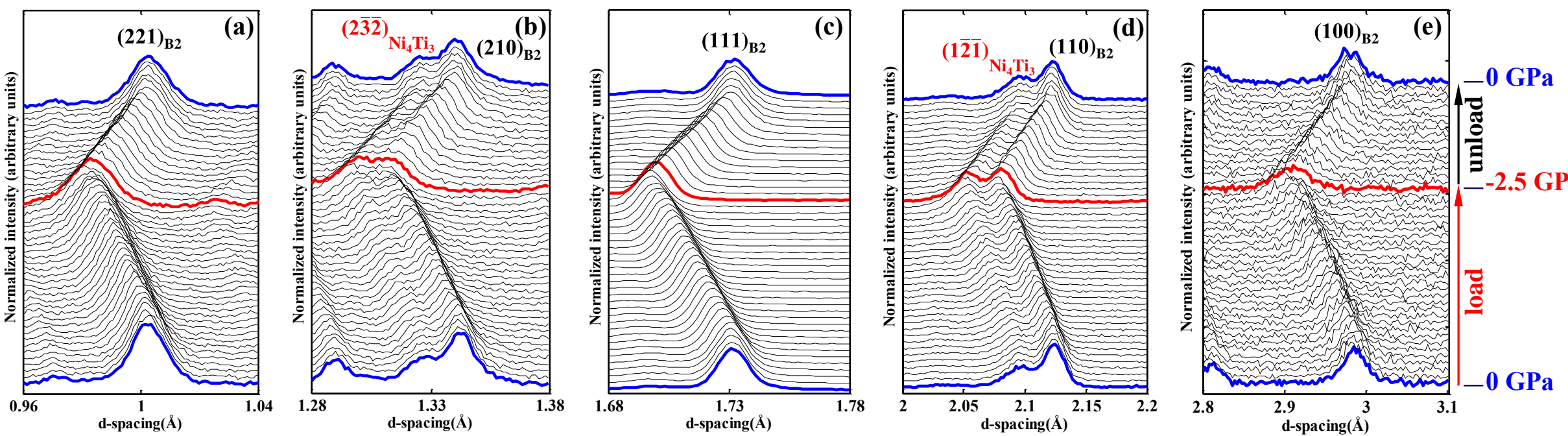

Lattice planes // to loading direction
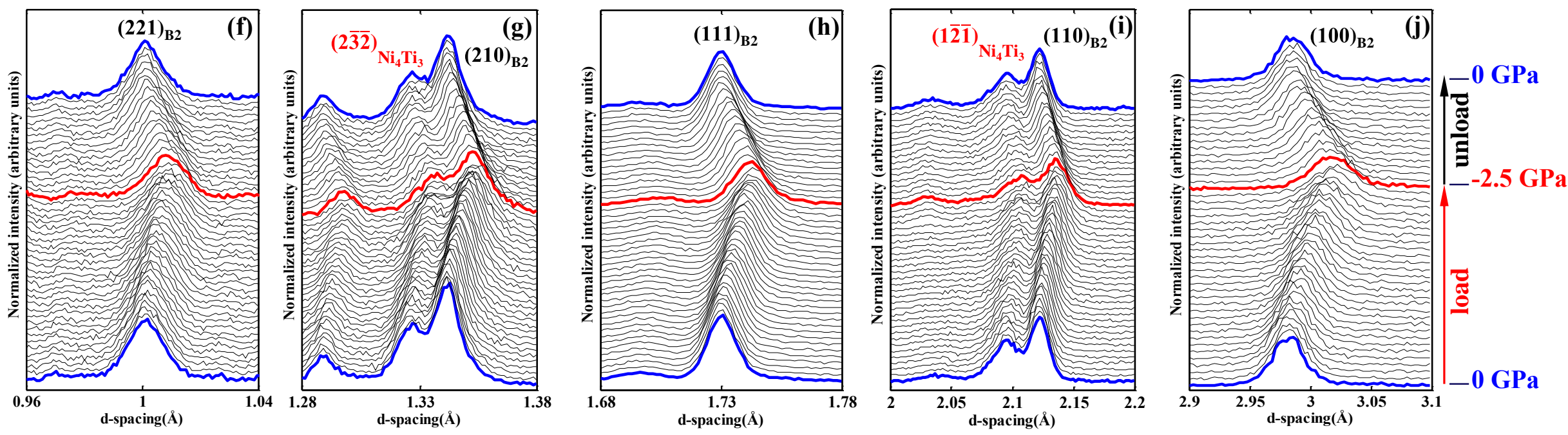

Fig. 10 
Lattice planes $\perp$ to loading direction

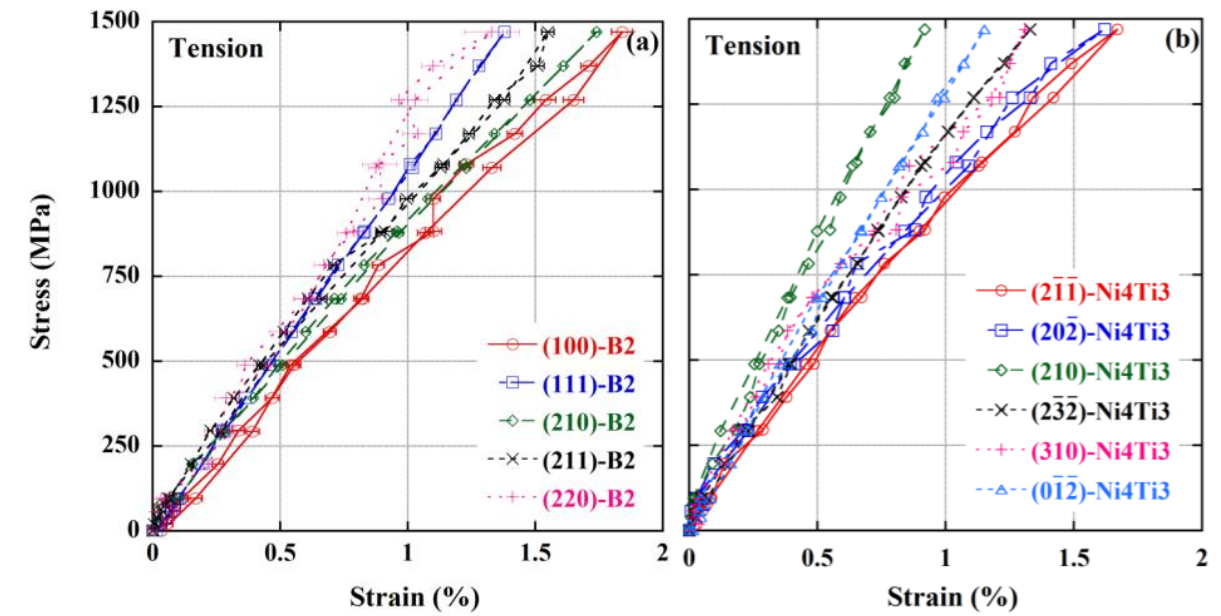

Lattice planes // to loading direction
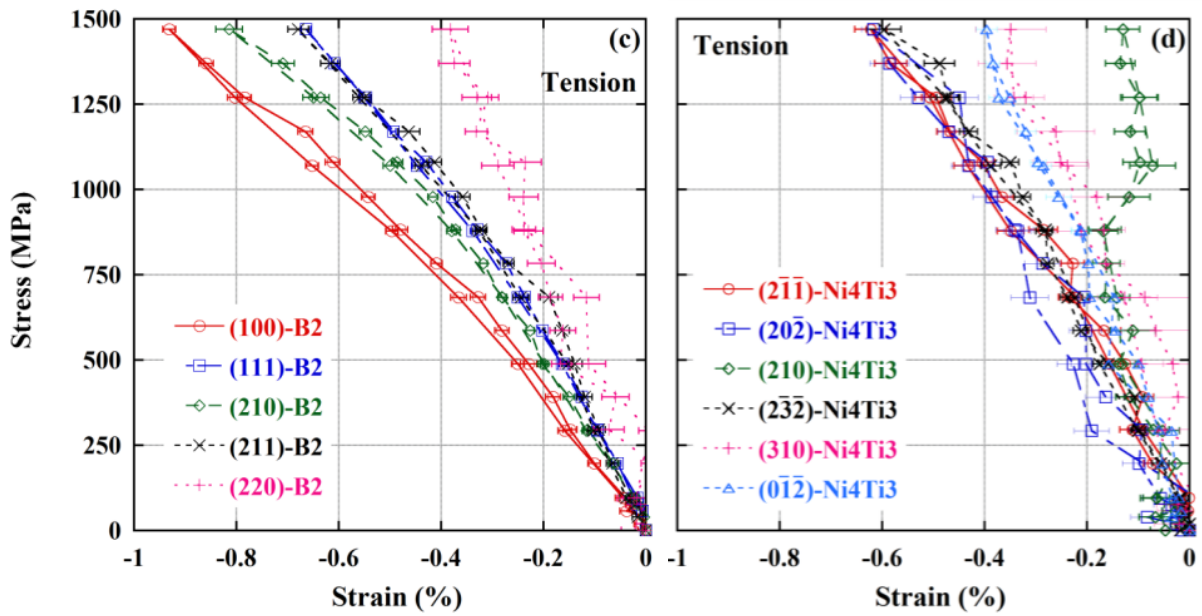
Lattice planes $\perp$ to loading direction
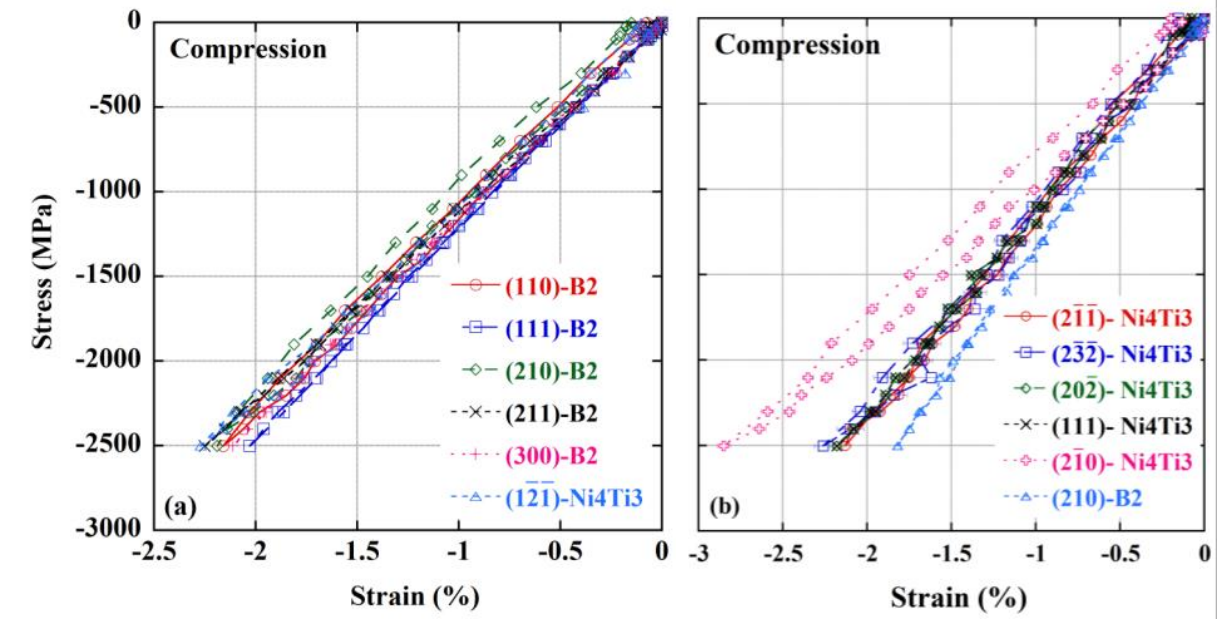

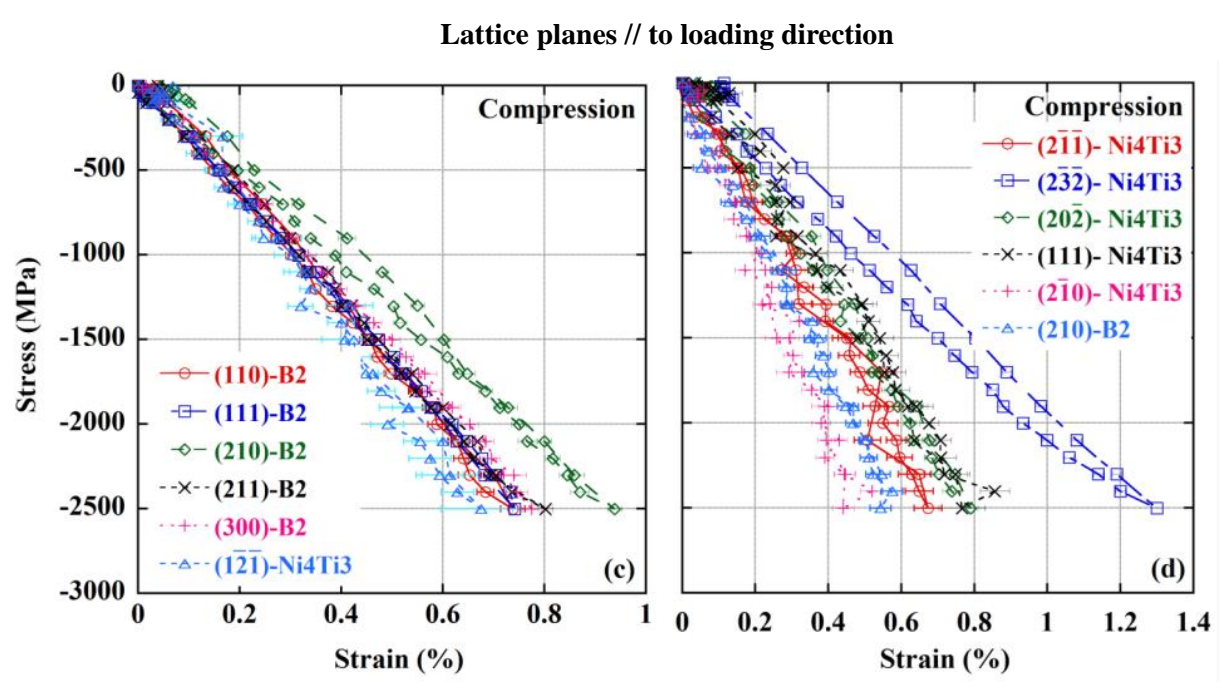

\section{Fig. 12}



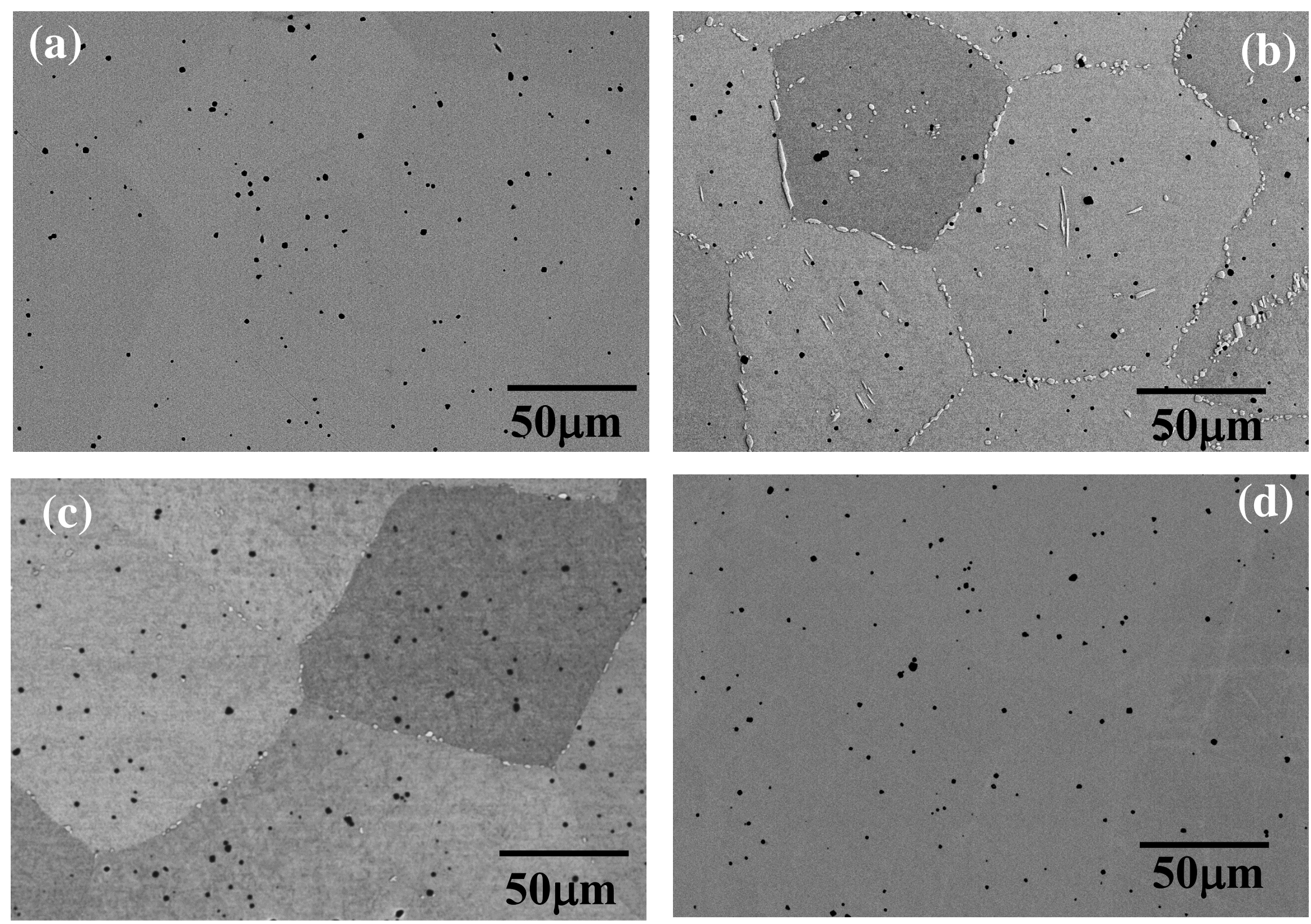

Fig. 15 

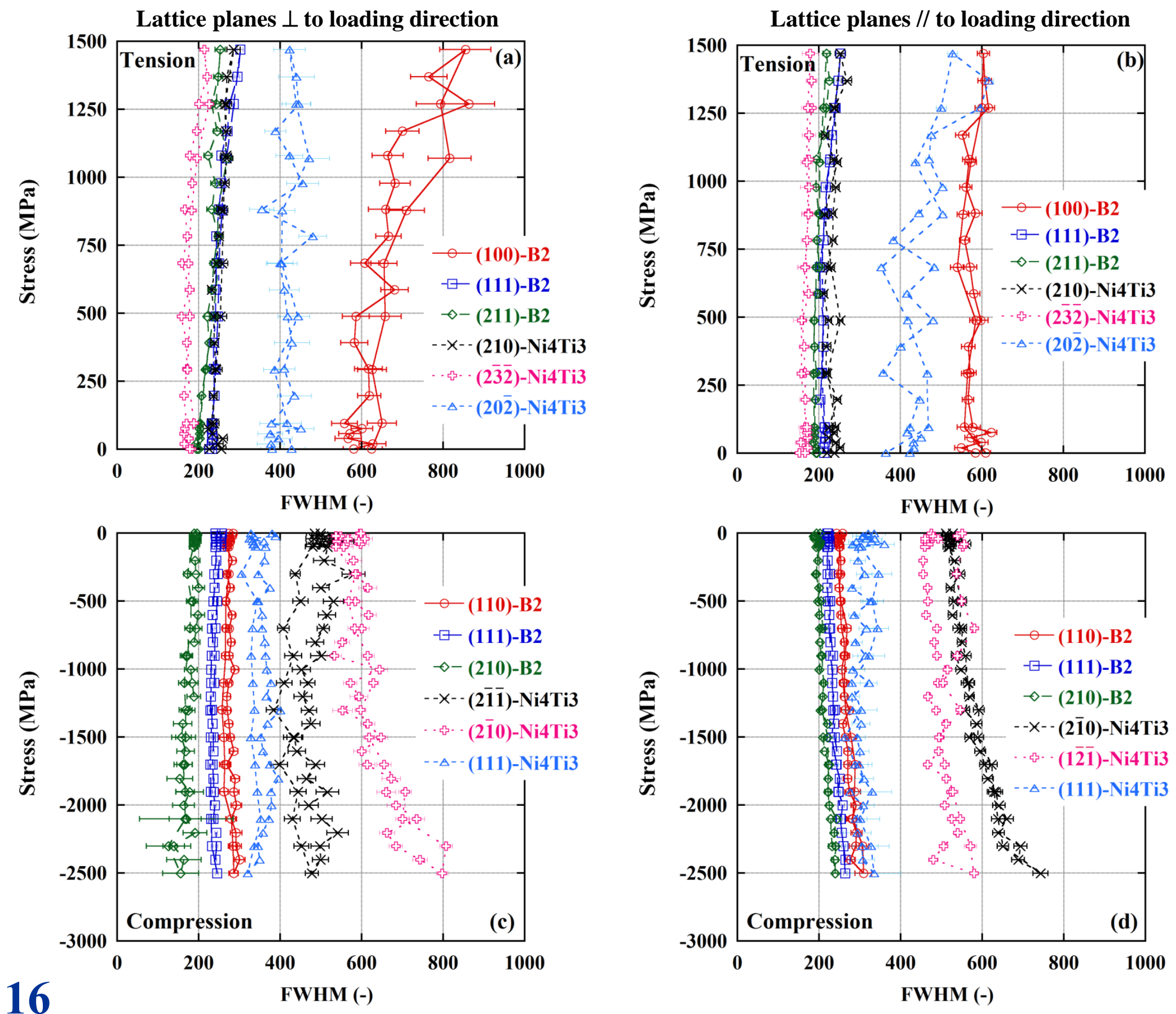